\title{
NATURE AND HISTORY OF THE ORGANIC COMPOUNDS IN COMETS: AN ASTROPHYSICAL VIEW
}

\author{
A.H. DELSEMME \\ Department of Physics and Astronomy \\ The University of Toledo \\ Toledo, OH 43606 U.S.A.
}

\begin{abstract}
The chemical similarities between comets, carbonaceous chondrites, and interstellar molecules and grains are reviewed first. The evolution of frosty interstellar grains is then followed during the collapse of a molecular cloud fragment and the subsequent formation of the Solar System. The paradigm clarifies the probable origin of the two populations of comets of different symmetry (the Oort Cloud and the Kuiper Belt) and implies an exogenous origin for all carbon and water on Earth. This origin is explained by the orbital diffusion of planetesimals that is required by the growth of protoplanets.
\end{abstract}

\section{Introduction}

In the 1970s, a growing similarity was found for the chemical compounds discovered in comets and in interstellar space. More recently, a possible causal connection explaining this similarity has been brought into sharp focus by a growing consensus on the scenario explaining the origin of the Solar System.

The emerging paradigm implies that interstellar grains, covered by a frost of organic molecules, were present in the molecular cloud fragment that collapsed into an accretion disk surrounding the protosun. Through the normal evolution of the disk, these grains were processed in different ways by heat and by radiation, and eventually clumped together into larger and larger objects. Depending on their radial location in the disk, their thermal processing was different. The outside objects were going to become the comets; the inside objects were going to become the building blocks of the terrestrial planets; at intermediate distances, they were going to build the parent bodies of those primitive meteorites called chondrites.

The parallel evolution of chondrites and comets, as well as their chemical similarities and differences, suggests that they must be considered together in their 
connection with interstellar molecules. Not only has the complex organic chemistry of carbonaceous chondrites been much better studied than that of comets, but carbonaceous chondrites have also played an important role in our understanding of the cosmic abundance ratio of the elements. The problem of the cosmic abundances will be briefly mentioned first. Later, our knowledge about organic matter in comets, in meteorites and in interstellar space will be compared. Finally, the paradigm that explains their similarities by a causal connection will be reviewed.

\section{Elemental Abundances in Comets}

\subsection{COSMIC ABUNDANCES IN ASTROPHYSICS}

Astrophysical observations have shown that the numerous population I stars present in our galactic vicinity have, by and large, the same elemental proportions as the Sun does. These proportions do not seem essentially different from those in the interstellar medium, at least when its gas and dust components are properly added together. This strengthens the belief that all Solar System objects were eventually differentiated from the same primitive mixture, whose composition must have been close to that observed in the present photosphere of the Sun (exceptions: lithium, beryllium and boron have been depleted in the Sun by well-understood thermonuclear reaction processes).

This belief has been considerably substantiated by the discovery that a large group of bodies coming from elsewhere in the Solar System, namely the chondrites (they represent $72 \%$ of all meteorite falls), also contain the same elemental proportions. This is strictly true for the elements that have escaped vaporization. In chondrites, the most volatile elements (in particular, H, C, N, O, S, the inert gases and labile metals) are depleted in variable amounts in the different classes of chondrites, but 50-odd elements are in strict solar proportions. Chondrites are fine-grain aggregates containing particles of widely different origins, as evidenced by their different thermal histories, their different degrees of oxidation and their different degrees of aqueous alteration. The particles must have been brought together by a cosmic process similar to a sedimentation and compacted later, presumably in parent bodies comparable to small asteroids 50 to $100 \mathrm{~km}$ in diameter.

Carbonaceous chondrites represent a class of chondrites in which $\mathrm{H}, \mathrm{C}, \mathrm{N}$, $\mathrm{O}, \mathrm{S}$ and the volatile metals have been least depleted. The $\mathrm{C}$ I subclass contains the most carbon (circa $4 \%$ ), sulfur (circa $6 \%$ ), free plus hydration water $(20 \%)$ and about $70 \%$ of siliceous material. This subclass seems to represent the most primitive and the least altered of the primitive meteorites, in spite of the fact that its volatile elements are still depleted in respect to the solar photosphere (a factor 
of about 3 for oxygen, 15 for carbon, 60 for nitrogen and 20,000 for hydrogen; see Table 1 for more extensive data).

In contrast, the correlation with the solar abundances of some 50 heavier elements is so good and the error bars so much smaller than in the solar photosphere, that the abundances in the C I carbonaceous chondrites have become the standards for cosmic abundance tables. It is clear, however, that photospheric and other data must still be used for the most volatile elements. The normalization of the two sets of data remains delicate, and tables are still being improved with better solar, astrophysical and meteoritic data. The most upto-date of these compilations is found in Anders and Grevesse (1989). This is indeed one of the references for Table 1 .

Table 1. Comparison of Elemental Abundances in the Sun, in CI Chondrites, and in Comet Halley. Normalized in Log Atom Numbers, With $\log \mathrm{N}_{\mathrm{H}}=12.00$ in the Sun.

\begin{tabular}{|c|c|c|c|c|c|}
\hline \multirow[t]{2}{*}{ ELEMENT } & \multirow{2}{*}{$\begin{array}{l}\text { SUN } \\
\text { (ANDERS AND } \\
\text { GREVESSE '89) }\end{array}$} & CI CHONDRITE & \multicolumn{3}{|c|}{ COMET HALLEY (THIS PAPER; SEE TEXT) } \\
\hline & & $\left({ }^{a}\right)$ & DUST ONLY & GAS ONLY & GAS + DUST \\
\hline $1 \mathrm{H}$ & 12.00 & $7.64 \pm 0.09$ & $8.89 \pm 0.08$ & $9.22 \pm 0.15$ & $9.39 \pm 0.12$ \\
\hline $6 \mathrm{C}$ & $8.56 \pm 0.04$ & $7.40 \pm 0.13$ & $8.49 \pm 0.08$ & $8.25 \pm 0.20$ & $8.69 \pm 0.14$ \\
\hline $7 \mathrm{~N}$ & $8.05 \pm 0.04$ & $6.24 \pm 0.04$ & $7.20 \pm 0.12$ & $7.95 \pm 0.22$ & $8.02 \pm 0.22$ \\
\hline 80 & $8.93 \pm 0.04$ & $8.42 \pm 0.02$ & $8.53 \pm 0.05$ & $8.95 \pm 0.15$ & $9.09 \pm 0.10$ \\
\hline $11 \mathrm{Na}$ & $6.33 \pm 0.03$ & $6.31 \pm 0.03$ & $6.58 \pm 0.20$ & $\ldots$ & $6.58 \pm 0.20$ \\
\hline $12 \mathrm{Mg}$ & $7.58 \pm 0.05$ & $7.58 \pm 0.02$ & $7.58\left({ }^{b}\right)$ & --- & $7.58\left(^{b}\right)$ \\
\hline $13 \mathrm{Al}$ & $6.47 \pm 0.07$ & $6.48 \pm 0.02$ & $6.41 \pm 0.10$ & --- & $6.41 \pm 0.10$ \\
\hline $14 \mathrm{Si}$ & $7.55 \pm 0.05$ & $7.55 \pm 0.02$ & $7.85 \pm 0.04$ & --- & $7.85 \pm 0.04$ \\
\hline $16 \mathrm{~S}$ & $7.21 \pm 0.06$ & $7.27 \pm 0.05$ & $7.44 \pm 0.12$ & $6.48 \pm 0.26$ & $7.48 \pm 0.24$ \\
\hline $19 \mathrm{~K}$ & $5.12 \pm 0.13$ & $5.13 \pm 0.03$ & $4.88 \pm 0.18$ & -.- & $4.88 \pm 0.18$ \\
\hline $20 \mathrm{Ca}$ & $6.26 \pm 0.02$ & $6.34 \pm 0.03$ & $6.38 \pm 0.11$ & $\cdots$ & $6.38 \pm 0.11$ \\
\hline $22 \mathrm{Ti}$ & $4.99 \pm 0.02$ & $4.93 \pm 0.02$ & $5.18 \pm 0.18$ & --- & $5.18 \pm 0.18$ \\
\hline $24 \mathrm{Cr}$ & $5.67 \pm 0.03$ & $5.68 \pm 0.03$ & $5.53 \pm 0.09$ & -- & $5.53 \pm 0.09$ \\
\hline $25 \mathrm{Mn}$ & $5.39 \pm 0.03$ & $5.53 \pm 0.04$ & $5.28 \pm 0.15$ & --- & $5.28 \pm 0.15$ \\
\hline $26 \mathrm{Fe}$ & $7.67 \pm 0.03$ & $7.51 \pm 0.01$ & $7.30 \pm 0.07$ & --- & $7.30 \pm 0.07$ \\
\hline $27 \mathrm{Co}$ & $4.92 \pm 0.04$ & $4.91 \pm 0.03$ & $5.06 \pm 0.22$ & -.- & $5.06 \pm 0.22$ \\
\hline $28 \mathrm{Ni}$ & $6.25 \pm 0.04$ & $6.25 \pm 0.02$ & $6.19 \pm 0.18$ & --- & $6.19 \pm 0.18$ \\
\hline
\end{tabular}

a For the $\mathrm{CI}$ chondrites, the abundances of $\mathrm{H}, \mathrm{C}, \mathrm{N}, \mathrm{O}$ are from Mason (1971); the other elements are from the revised values of Anders and Grevesse (1989).

b Comet Halley's abundances are normalized for $\mathrm{Mg}=7.58$; the dust-to-gas mass ratio is 0.8 and the error bars include a variation of this ratio from 0.6 to 1.0 . 
Table 2. Light Elements in Some Bright Comets and Mean Ratios of Atom Numbers in the Volatile Fraction

\begin{tabular}{lll}
\hline ELEMENT & $\begin{array}{l}\text { BRIGHT COMETS } \\
\text { (DELSEMME 1985) }\end{array}$ & $\begin{array}{l}\text { COMET HALLEY } \\
\text { (DELSEMME 1988) }\end{array}$ \\
\hline $\mathrm{H} / \mathrm{O}$ & $1.8 \pm 0.4$ & $1.9 \pm 0.4$ \\
$\mathrm{C} / \mathrm{O}$ & $0.20 \pm 0.10$ & $0.20 \pm 0.05$ \\
$\mathrm{~N} / \mathrm{O}$ & $0.10 \pm 0.05$ & $0.10 \pm 0.05$ \\
$\mathrm{~S} / \mathrm{O}$ & $0.003 \pm 0.0015$ & $0.01 \pm 0.005$ \\
\hline
\end{tabular}

\subsection{ELEMENTAL ABUNDANCES IN COMET HALLEY}

I showed (Delsemme 1982) that the abundance ratios of the light elements were about the same in the volatile fraction of several bright comets of the 1970s. The 1986 passage of Comet Halley gave about the same results. The last column of Table 2 is based on an extensive discussion of all available data from Comet Halley (Delsemme 1988). Only the $\mathrm{H} / \mathrm{O}$ ratio has been slightly changed: this recent revision is implied by the balance sheet of all elements (Table 6).

Before the passage of Comet Halley, all that was known for sure about cometary dust was that it showed the emission bands of silicates in the thermal infrared and that it had a very low albedo, suggesting the presence of carbon to darken the silicates. The results of Krueger and Kissel (1987) for the dust of Comet Halley give, for the first time, the mean chemical composition of dust in any comet. These results will be discussed in the next section. Let us consider the elements first. Jessberger et al. (1988) give details on the major-element composition of Comet Halley's dust. I have translated their results in the cosmic abundance table used in astrophysics $(\log H=12)$. The normalization is done for $\log \mathrm{Mg}=7.58$ because they use $\mathrm{Mg}$ to normalize a total of 79 high-quality mass spectra from PUMA 1, the impact ionization mass spectrometer on board the VEGA 1 spacecraft. The results are given in the Table 1 column labelled "DUST ONLY."

Since the light elements $\mathrm{H}, \mathrm{C}, \mathrm{N}, \mathrm{O}$ and $\mathrm{S}$ are present in volatile molecules observed in the gas phase, as well as in more stable molecules present in the dust grains, the dust-to-gas mass ratio is needed to normalize gas to dust and know the total abundance for each comet. This ratio is not easy to measure. However, Finson and Probstein (1968) developed a method to study the size distribution of 
dust grains, from the isophotes that can be drawn on a photograph of the dust tail. A byproduct of the method is the distribution of the initial velocities of the dust grains, when they were dragged away from the nucleus by the vaporizing gases. This distribution, as a function of the dust size, depends on the amount of dust loading the gas. I have described the technique in more detail, and used it as a measure of the dust-to-gas ratio (Delsemme 1982). Although the technique is not very accurate, any other technique implies a much larger number of unwarranted assumptions. For instance, Newburn and Spinrad (1985), who published dust-togas mass ratios for 17 comets, often have to assume not only a dust albedo and a nominal expansion rate of gas, but also a nominal size distribution for the dust grains (deduced from another comet for small grains, unknown for those large grains that may contain most of the mass).

Another problem is that the dust-to-gas ratio observed in a dust tail by the Finson-Probstein method often shows wide fluctuations from the steady state. These fluctuations had been predicted by Mendis and Brin $(1977,1978)$ as coming from the blowoff of a mantle of outgassed dust for comets coming to perihelion. I substantiated (Delsemme 1982) such a blowoff for Comet Arend-Roland six days before perihelion, and found that, using Finson and Probstein's data, it was possible to show that the dust-to-gas ratio $\mathrm{M}$ came smoothly to a steady-state value of $0.8 \pm 0.2$. Only one other ratio has been established by the same method: that of Comet Bennett 1970 II (Sekanina and Miller 1973). The error bars were larger for this comet. My discussion (Delsemme 1982) suggests that $\mathbf{M}$ was somewhere between 0.2 and 1.0, remaining consistent with the previous value of $0.8 \pm 0.2$.

However, we now need $\mathrm{M}$ for Comet Halley. A Finson-Probstein study of the tail isophotes has been done carefully (Fulle 1987, Fulle et al. 1987), but its major result was to demonstrate that the comet was very far from the steady state during the flybys. The low values of $\mathrm{M}(0.2$ or 0.3$)$ found during the flybys are consistent with the establishment of an outgassed mantle of dust after perihelion, but are irrelevant for the steady state. There is a further complication: from the discrete data of DIDSY, McDonnell et al. (1986) suggest the existence of a large amount of massive grains not taken into account in the production rates of dust. Radar observations of comets Halley and IRAS-Araki-Alcock have confirmed that a large amount of centimeter- to millimeter-sized grains contribute a significant fraction to the dust mass (Campbell et al. 1989, Harmon et al. 1989). Finally, the dust used by Kissel et al. (1986) was collected mostly from $60,000 \mathrm{~km}$ to $10,000 \mathrm{~km}$ from the nucleus, but its grains were still vaporizing up to $20,000 \mathrm{~km}$, as demonstrated by the extended source of CO detected by Eberhart et al. (1987).

This lengthy discussion was needed to establish that we have no good assessment of $\mathbf{M}$ for Comet Halley. The only way to go further is to assume that all comets are essentially similar (see arguments in Delsemme 1987) and use $\mathrm{M}=0.8$. This is what has been done in Table 1. The column "DUST ONLY" uses the abundances of Jessberger et al. (1988) measured for 79 dust grains; they 
have been translated into the log of atom numbers, normalized for $\log$ $\mathrm{N}(\mathrm{Mg})=7.58$. The column "GAS ONLY" uses the Table 2 ratios and normalizes them in such a way that the total mass of the gas yields $M=0.8$. The cometary abundances given by the sum (gas plus dust) are found in the last column of Table 1.

Figure 1 shows the major results of Table 1 for the volatile elements $\mathrm{H}, \mathrm{C}$, $\mathrm{N}, \mathrm{O}$ and $\mathrm{S}$ and the three major metals $\mathrm{Fe}, \mathrm{Si}$ and $\mathrm{Mg}$. It is a very significant result to find that, in respect to solar abundances, $\mathrm{H}$ is depleted in Comet Halley by about 500 , whereas $\mathrm{C}, \mathrm{N}, \mathrm{O}, \mathrm{S}$ are solar--within the error bars. A puzzling feature is the depletion of iron by at least a factor of two; it is delicate to attribute any significance to this fact, because it could come from a chance fluctuation in the sampling (we deal here with 79 microscopic grains).

In Figure 2, we directly compare the abundances in Comet Halley and in the Sun, still normalized with $\mathrm{Mg}$. The error bars are sufficiently close to the $45^{\circ}$ diagonal to conclude that the abundances are likely solar in Comet Halley, except for hydrogen (and presumably helium and neon), which is depleted by several orders of magnitude. This is exactly the definition of what I have called in the past a "primitive" mixture (Delsemme 1977). It is also easy to find which mass ratio would give the least square fit for $\mathrm{C}, \mathrm{N}, \mathrm{O}$ to reach solar abundances in comets. This is the dust-to-gas mass ratio $\mathrm{M}=0.64 \pm 0.30$. It is within the error bars of the ratio determined for comets Arend-Roland $(0.8 \pm 0.2)$ and Bennett $(0.6 \pm 0.4)$ (Delsemme 1982).

Had we used silicon instead of magnesium for the normalization of all the metals, Figure 1 shows that the Comet Halley data for N, C, O and S would fit even better with the solar data. Since $M=0.8$ was used in Figure 1 , this gives another assessment of the uncertainty on $\mathrm{M}$. It is concluded that the dust-to-gas mass ratios of comets Arend-Roland and Halley were not far apart, probably between 0.6 and 1.0, and that the elemental abundances of comets are solar (except for $\mathrm{H}$ and presumably for $\mathrm{He}$ and $\mathrm{Ne}$ ).

A final word of caution: We have many reasons to believe that a certain number of icy particles (the so-called "CHON" particles) that have been picked up the closest distances (10 to $20,000 \mathrm{~km}$ ) to the nucleus, would have been at least partially vaporized before reaching $1 \times 10^{5}$ to $2 \times 10^{5} \mathrm{~km}$, beyond which distance the gaseous fraction was measured by different means. It is therefore possible that a small fraction of the elements has been counted twice in Table 1. Eberhardt et al. (1987, Figure 2) have indeed discovered the existence of an extended source of $\mathrm{CO}$ reaching $20,000 \mathrm{~km}$ around Comet Halley's nucleus. I showed (Delsemme 1988) that the flux produced by this extended source is $(8 \pm 2) \%$ of the amount of oxygen, in reasonable agreement with the $7 \%$ deduced from the vaporization of the CHON grains. We should therefore diminish oxygen and carbon by this amount in the "GAS ONLY" column of Table 1, which would bring the "GAS + DUST" column (in log units) 0.02 closer to the solar abundances of oxygen and carbon. Hence the existence of an icy halo of volatile 


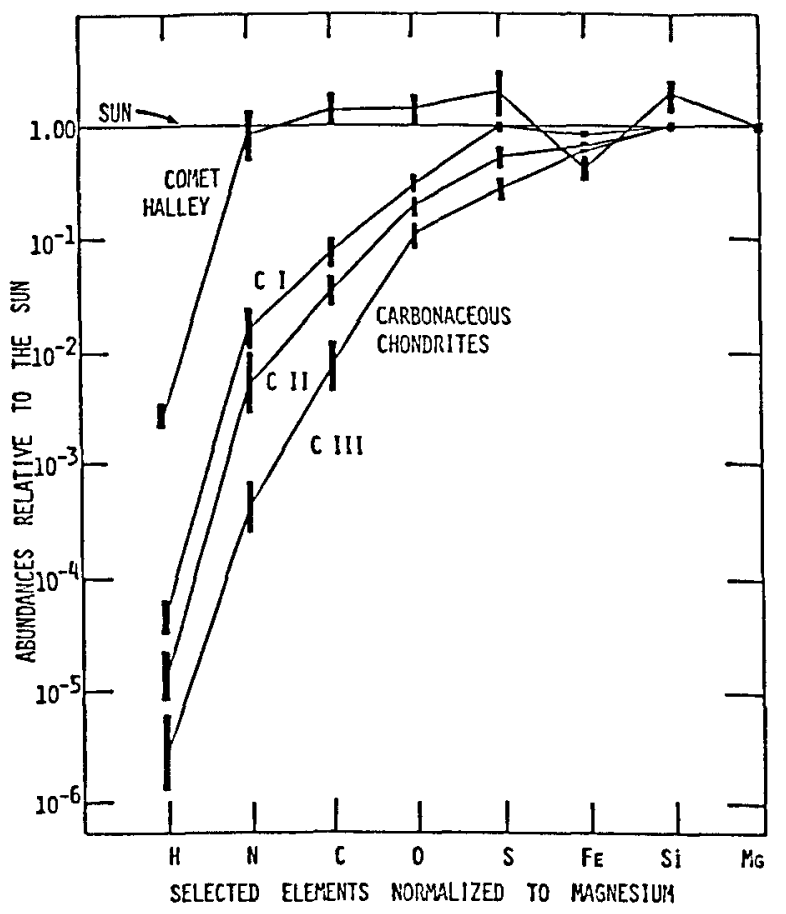

Figure 1. Comparison of the relative elemental abundances in the Sun, in Comet Halley, and in carbonaceous chondrites. The thick solid lines are the error bars for Comet Halley, whereas in the chondrites, they refer to the actual dispersion of the results for different chondrites in the same group. The normalization using magnesium puts the cometary abundances of the elements $\mathrm{C}, \mathrm{O}, \mathrm{S}$ and Si slightly higher than in the Sun. The normalization could use silicon instead of magnesium. Then the $\mathrm{C}, \mathrm{O}, \mathrm{S}$ abundances would be closer to the solar ones, but $\mathrm{Fe}$ would be even more depleted in Comet Halley. The significance of this depletion is not understood. It could, of course, come from a random fluctuation of the iron abundance in the 79 dust grains used by Jessberger et al. (1988).

grains (Delsemme and Miller 1970, 1971) does not introduce any major correction in Table 1. For convenience, Table 3 gives the nominal values for the elemental ratios of the volatile elements as they appear in Table 1 in the "GAS + DUST" column.

Two important conclusions can be derived from the fact that the elemental abundances of Comet Halley are the same as the Sun's (except for H). The first one is that, since a radial differentiation is likely to perturb the solar proportions 


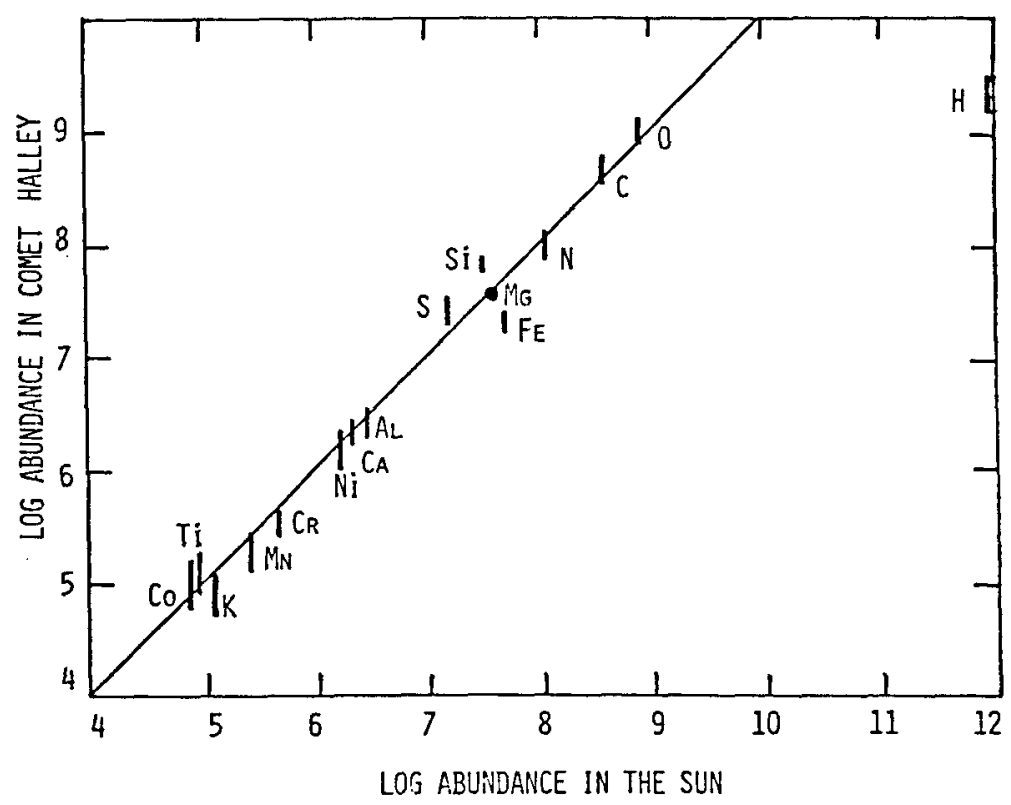

Figure 2. The elemental abundances known in Comet Halley are compared with those in the Sun. The units are those used in astrophysics, with $\log N=12$ for hydrogen. The data come from Table 1 . The error bars for the solar abundances are smaller than those for Comet Halley; for this reason, they have been omitted here. The fit suggests that the abundances in Comet Halley are close to the solar ones and the result can probably be generalized to all comets.

in the different layers, Comet Halley is likely to be undifferentiated radially, reinforcing the indirect arguments developed previously (Delsemme 1982). The second one is that if Comet Halley originated from the same nebular reservoir as the Sun (as implied by its elemental abundances), then all comets are likely to come from the same reservoir, and all pristine comets must be chemically alike.

\subsection{ISOTOPIC RATIOS}

Before the passage of Comet Halley, the only isotopic ratio measured in comets was the ${ }^{12} \mathrm{C} /{ }^{13} \mathrm{C}$ ratio measured from the (1-0) band of the $\mathrm{C}_{2}$ molecule. A blend of this band with $\mathrm{NH}_{2}$ makes the measurement uncertain even at high resolution. The results look somewhat dependent on the comet as well as on its perihelion distance; the ${ }^{12} \mathrm{C} /{ }^{13} \mathrm{C}$ ratio seems to vary from 70 to 140 or even sometimes much beyond. However, because of the width of the error bars, it was generally assumed that the ratio was consistent with the terrestrial value of 89 
Table 3. Elemental Ratios in Atom Numbers for $\mathrm{H}, \mathrm{C}, \mathrm{N}, \mathrm{O}$, and $\mathbf{S}^{\mathrm{a}}$

\begin{tabular}{llllll}
\hline RATIOS & SUN & COMETS & CI CHONDRITES & COMET DUST & COMET GAS \\
\hline H/O & 1175 & 2.00 & 0.17 & 2.29 & 1.86 \\
C/O & 0.43 & 0.40 & 0.10 & 0.91 & 0.20 \\
N/O & 0.13 & 0.09 & 0.007 & 0.005 & 0.10 \\
S/O & 0.02 & 0.03 & 0.07 & 0.08 & 0.003 \\
\hline
\end{tabular}

a The ratios are all derived from Table 1 .

(Lambert and Danks 1983); yet, its apparent variation of some 20\% in different spectra of Comet Kohoutek (Danks et al. 1974) does not seem to have been properly explained. For comparison, the interstellar ratio in the solar neighborhood, measured optically in the $\mathrm{CH}^{+}$band by Hawkins and Jura (1987), is constant within $12 \%$ in four different lines of sight and is $43 \pm 4$. The traditional explanation for the high solar value of 89 is that five billion years ago this was the solar neighborhood value, which was quenched in the Solar System during its formation. The interstellar value would have changed since, because of the ${ }^{13} \mathrm{C}$ enrichment due to the $\mathrm{CNO}$ cycle in thermonuclear burning of the young population I stars in the solar neighborhood (Truran 1985). This gradual enrichment is not unanimously accepted, though (Schramm 1985).

Wyckoff et al. (1989) have resolved the ${ }^{13} \mathrm{CN}$ rotation lines in Comet Halley. They deduce an isotopic ratio of $65 \pm 9$ for the $\mathrm{CN}$ molecule. It is dangerous to overinterpret this result because it is not $\mathrm{C}_{2}$ but a different molecule, and fractionation effects (which include the vaporization from the comet nucleus) may be different. Measurements in the interstellar medium on different molecules also cover a very large range of values, from 40 to 90 (Wannier 1980). The slight isotopic anomaly of $\mathrm{CN}$ in Comet Halley must probably be considered as having the same origin as the larger isotopic anomalies $\left({ }^{13} \mathrm{C}\right.$ enhancements) found in special grains of carbonaceous chondrites (Swart et al. 1983, Niederer et al. 1985, Zinner et al. 1987). Jessberger and Kissel (1987) also found some grains in Comet Halley with an anomalously high ${ }^{12} \mathrm{C} /{ }^{13} \mathrm{C}$ ratio, but the mass spectra blends ${ }^{13} \mathrm{C}$ with $\mathrm{CH}$, so the quantitative measurements of ${ }^{13} \mathrm{C}$ are difficult.

Other isotopic abundances have also been obtained in Comet Halley, the most important probably being the $\mathrm{D} / \mathrm{H}$ ratio of water, found to be between 60 and 480 parts per million (ppm) by Eberhardt et al. (1986). This ratio is 
consistent with the 150 -ppm value of sea water, and definitely higher than the 20ppm value of the interstellar medium, in agreement with a cometary origin of seawater (see Section 5.7). The same authors also report that ${ }^{18} \mathrm{O} /{ }^{16} \mathrm{O}=$ $(23 \pm 6) \times 10^{-4}$ in Comet Halley, in agreement within the error limits with the value of $20 \times 10^{-4}$ of seawater, which is also the value elsewhere in the Solar System.

Although we still lack much data, nothing has been found yet that would not be consistent with the cometary material originating from the same original reservoir as the rest of the Solar System, with it being understood that this reservoir may contain numerous isotopic anomalies already detected microscopically in meteorites. These anomalies might have been even less homogenized in comets because of their cooler temperature history (see Sections 3.2 and 5.8). In particular, the isotopic value ${ }^{12} \mathrm{C} /{ }^{13} \mathrm{C}$ found for $\mathrm{CN}$ does not imply an exogenous origin of Comet Halley, but only that the parent molecule has kept the signature of an isotopic anomaly present in interstellar grains.

\section{Organic Compounds in Comets}

\subsection{ORGANIC COMPOUNDS IN COMETARY SPECTRA}

At the end of the 19th century, organic molecular fragments such as $\mathrm{CN}$, $\mathrm{C}_{2}$ and $\mathrm{CO}^{+}$had already been identified in the spectra of cometary heads and tails. $\mathrm{CH}$ was first suggested by Bobrovnikoff (1931) and positively identified by Nicolet (1938). By 1950, the seven radicals $\mathrm{CH}, \mathrm{CN}, \mathrm{C}_{2}, \mathrm{C}_{3}, \mathrm{OH}, \mathrm{NH}$, and $\mathrm{NH}_{2}$, as well as the five ions $\mathrm{CH}^{+}, \mathrm{CO}^{+}, \mathrm{CO}_{2}{ }^{+}, \mathrm{OH}^{+}$, and $\mathrm{N}_{2}^{+}$, had been identified. At that time, it had also become clear that these molecular fragments were due to the decay of unobservable "parent" molecules vaporizing from the cometary nucleus. This decay was itself due to the parent molecules' photodissociation or photoionization produced by the ultraviolet light of the Sun. Since all observed fragments were built with the four elements $\mathrm{C}, \mathrm{H}, \mathrm{O}, \mathrm{N}$, a non-negligible fraction of the parent molecules present in the nucleus had to be organic matter (Table 4).

Just before the 1986 passage of Comet Halley, 39 different molecular and atomic fragments had been identified; among them, 11 radicals and 4 ions were from organic matter (see the review in Delsemme 1985); $83 \%$ by mass of the volatile fraction was water, and $14 \%$ was organic matter (Delsemme 1985). The non-volatile component was less well characterized, since only the emission features of silicates were identified in the infrared spectrum of the onset of the dust tail. Quantitative knowledge of cometary chemistry really got started, at least for the volatile fraction, with the comparison of data from comets Arend-Roland (1957 III), Seki-Lines (1962 III), Bennett (1970 II), Kohoutek (1973 XII) and West (1976 VI), whereas the dusty fraction had to wait for the Comet Halley flybys by the two VEGAs and the Giotto spacecraft. 
Table 4. Chemical Species Identified in the Cometary Head ${ }^{a}$

1. BY VISUAL, ULTRAVIOLET, INFRARED AND RADIOWAVE SPECTROSCOPY - ORGANIC:

hydrocarbons: $\mathrm{C}, \mathrm{C}_{2}, \mathrm{C}_{3}, \mathrm{CH}$ (isotope ratio ${ }^{12} \mathrm{C} /{ }^{13} \mathrm{C}$; Wehinger et al. 1986)

with nitrogen: $\mathrm{CN}, \mathrm{HCN}, \mathrm{CH}_{3} \mathrm{CN}$ (isotope ratio ${ }^{14} \mathrm{~N} /{ }^{15} \mathrm{~N}$; Wehinger et al. 1986)

with oxygen: $\mathrm{HCO},\left(\mathrm{H}_{2} \mathrm{CO}\right), \mathrm{CO}_{2}$ (Combes et al. 1986)

- INORGANIC:

ammonia group: $\mathrm{NH}, \mathrm{NH}_{2},\left(\mathrm{NH}_{3}\right),\left(\mathrm{NH}_{4}\right)$

water group: $\mathrm{H}, \mathrm{O}, \mathrm{OH}, \mathrm{H}_{2} \mathrm{O}$ (Mumma et al. 1986: ortho/para in $\mathrm{H}_{2} \mathrm{O}$ )

sulfur group: $\mathrm{S}, \mathrm{S}_{2}$

- METALS:

$\mathrm{Na}, \mathrm{K}, \mathrm{Ca}, \mathrm{V}, \mathrm{Mn}, \mathrm{Fe}, \mathrm{Co}, \mathrm{Ni}, \mathrm{Cu}$ (Sun-grazing comets)

- IONS:

Organic: $\mathrm{C}^{+}, \mathrm{CH}_{+}, \mathrm{CO}^{+}, \mathrm{CO}_{2}^{+}$

with $\mathrm{N}: \mathrm{N}^{+}{ }_{2}$

with S: $\mathrm{H}_{2} \mathrm{~S}^{+}$

with $\mathrm{O}: \mathrm{OH}^{+}$

metal: $\mathrm{Ca}^{+}$

2. FROM PEAKS IN MASS SPECTRA DURING SPACECRAFT FLYBY

$\mathrm{H}_{3} \mathrm{O}^{+}$(in Giacobini-Zinner: Olgivie et al. 1986)

(in Halley: Gringauz et al. 1986, Balsiger et al. 1986, Korth et al. 1986).

$\left(\mathrm{H}_{2} \mathrm{CO}\right)_{\mathbf{n}}$ (from ionic fragments; Huebner 1987)

$\mathrm{NH}^{+}{ }_{4}, \mathrm{NH}^{+}{ }_{3} ; \mathrm{CH}^{+}{ }_{4}, \mathrm{CH}^{+}{ }_{3} ; \mathrm{S}^{+}{ }_{2}, \mathrm{CS}^{+}, \mathrm{CS}^{+}{ }_{2}$ (Allen et al. 1987)

$\mathrm{C}_{3} \mathrm{H}^{+}{ }_{3}$ (Korth et al. 1989)

$\mathrm{HCO} \cdot \mathrm{OH}$ and $\mathrm{H}_{2} \mathrm{CO}$ in CHON grains (Kissel and Krueger 1987)

a References for post-1985 discoveries only; prior to that, see Delsemme 1985. 
Table 5. Dust in Comet Halley Mean Chemical Composition in Mass Percent ${ }^{\text {a }}$

\begin{tabular}{llll}
\hline \multicolumn{2}{c}{ ORGANIC 33\% } & \multicolumn{2}{c}{ INORGANIC 67\% } \\
\hline $\begin{array}{l}\text { Unsaturated } \\
\text { Hydrocarbons } \\
\mathrm{H}, \mathrm{C}+\mathrm{O}\end{array}$ & $16.0 \%$ & Silicates & $51.5 \%$ \\
$\mathrm{H}, \mathrm{C}+\mathrm{N}$ & $5.2 \%$ & FeS (Troilite) & $6.0 \%$ \\
$\mathrm{H}, \mathrm{C}+\mathrm{S}$ & $4.5 \%$ & $\mathrm{C}$ (Graphite) & $3.0 \%$ \\
Water & $1.8 \%$ & S (Sulfur) & $1.0 \%$ \\
\hline
\end{tabular}

a Interpreted from Krueger and Kissel 1987.

\subsection{THE DUST IN COMET HALLEY}

The most detailed results on the dust of Comet Halley seem to have been brought about by the dust impact spectrometer PUMA of the VEGA 1 flyby (Kissel et al. 1986, Krueger and Kissel 1987). Table 4 gives the mean composition of the icy and dusty particles analyzed by PUMA, mostly in the 60,000- to 10,000 $\mathrm{km}$ range. One of the major surprises of the dust analysis was the discovery of how much the grains vary in composition. Most of the grains are of submicrometer size, typically 0.1 to 0.2 micrometer, with a few larger grains. However, the larger grains dominate in mass. The mean composition of Table 5 is averaged over 80 particles. Of course the major problem of the PUMA and PIA experiments was the fast flyby velocities of the spacecraft encounters with Halley. For this reason, there is no realistic calibration of the impact ionization yields for particle collisions in the $70-$ to $80-\mathrm{km} / \mathrm{s}$ range, and it is tempting-although possibly unjustified--to explain some of the unexpected results by variations in the ionization yields.

There are, however, a few conclusions that are difficult to dismiss. In particular, the scatter of the elemental composition of individual grains is considerably larger than that in submicrometer volumes of meteoritic and interplanetary particles (Brownlee et al. 1987). For instance, the distribution of the $\mathrm{Fe} /(\mathrm{Fe}+\mathrm{Mg})$ ratio in a chondrite matrix is narrow: it goes approximately from 0.3 to 0.7 , with a strong peak at 0.5 . In the grains of Comet Halley, the distribution goes irregularly from 0.0 to 1.0 ; that is, it includes grains from pure iron to pure magnesium. Figure 3 reproduces the histogram of the $\mathrm{Fe} /(\mathrm{Fe}+\mathrm{Mg})$ atom ratios in the 74 grains of Halley's dust, from Jessberger et al. (1988). 


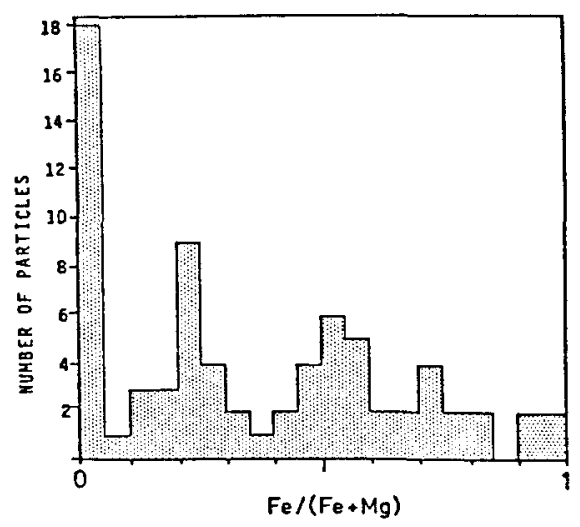

Figure 3. Histogram of the $\mathrm{Fe} /(\mathrm{Fe}+\mathrm{Mg})$ ratio in atom numbers of 74 dust grains in Comet Halley. In contrast to the distribution of micrometer-sized grains in the chondrites' matrix, this distribution is not centered only around the 0.5 ratio. Hence, the chemical diversity of grains is much wider in comets than in chondrites. There were, in particular, 18 grains with less than 5\% iron and more than 95\% magnesium, and two grains with more than $95 \%$ iron and less than 5\% magnesium (from Jessberger et al. 1988).

The latter authors distinguish four families of particles by cluster analysis of the elemental abundances in their mass spectra. CHON particles are in the first two families; silicates are in the last two. The abundance dispersions are very large, but on the average, the families contain the following proportions:

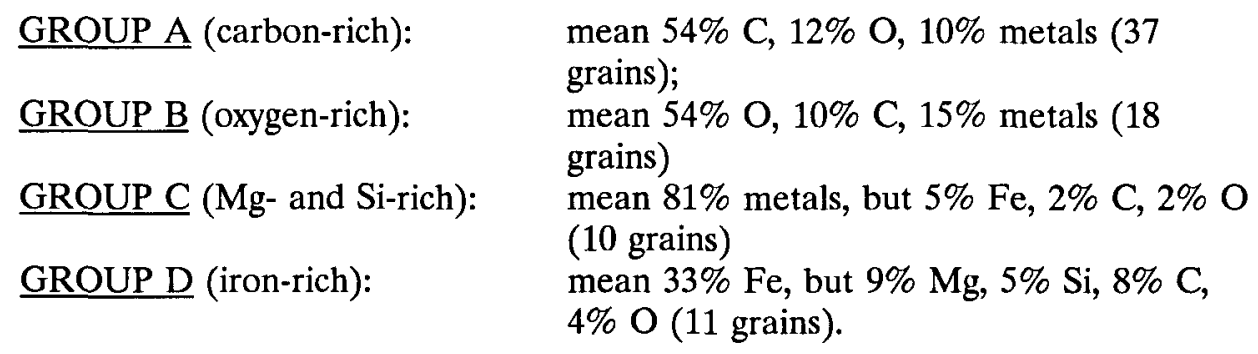

The results can be interpreted by saying that cometary dust is an extreme example of the same kind of sedimentation that was already mentioned for the grains present in the matrix of chondrites. A large degree of uniformity in bulk chemical composition also exists in comets, since on the average the solar abundances are closely reached for most elements, yet the individual grains are much more variable in chemical composition in comets than in chondrites. This large variability from grain to grain suggests the absence of alteration or 
metamorphism. The absence of any thermal processing during the history of the grains is also demonstrated by the outgassing that takes place in the nucleus as soon as the temperature reaches $180 \mathrm{~K}$. The two metal-rich families $\mathrm{C}$ and $\mathrm{D}$, although they may contain silicates (Jessberger et al. 1988), do not seem to contain enough oxygen to form large amounts of silicates or metallic oxides. As a matter of fact, groups $\mathrm{A}, \mathrm{C}$ and $\mathrm{D}$ seem to contain much reduced carbon or metals, whereas group B seems to be formed of completely oxidized particles.

Krueger and Kissel (1987) interpret the mass spectra (Table 5) by suggesting that the organic fraction contains $16 \%$ unsaturated hydrocarbons, with a bulk $\mathrm{H} / \mathrm{C}$ ratio close to 0.67 ; there is also $5.5 \%$ of oxygen-containing species, probably formic acid and formaldehyde in equal amounts; then, $4.5 \%$ of nitrogencontaining species, a mixture of hydrogen cyanide, acetonitrile, aminoethylene, pyrrole, pyridine, and pyrimidine (Krueger and Kissel mention that the identification corresponds to 50 coincidence pairs in mass spectra). Purine and adenine seem to be present in several grains, whereas there is no indication of amino-acids. Finally, there is $1.8 \%$ of sulphur-containing species. Some molecules contain several oligo elements; amino-methanol seems to be present, as well as some oxygen atoms that seem to be occasionally exchanged for sulphur atoms.

The $78 \mathrm{~km} / \mathrm{s}$ velocity of the impact must have destroyed a very large number of big molecules; it is already remarkable that recognizable patterns of molecular fragments still exist for large condensed heterocyclics. The high-velocity flybys of Comet Halley have provided data and insights that come tantalizingly close to a preliminary understanding of the chemistry of the solid grains, but they have opened the door to a larger number of questions about the positive identification of almost all organic molecules. It is now clearer than ever that lowvelocity flybys are needed for the future cometary missions, in order to not destroy complex organic molecules. Other techniques of chemical analysis, such as gas chromatography, should also be coupled with mass spectrometry to allow positive and unique identifications of many organic molecules.

\subsection{THE VOLATILE FRACTION OF COMET HALLEY}

With the study of Comet Halley, the possibility of building a consistent model of the volatile fraction escaping from the nucleus has been reached for the first time. Previous papers (Delsemme 1982, 1988) contain all the details on how to build such a model; I will not repeat them here. Table 6 gives a slightly improved version of the model, which is in quantitative or qualitative agreement with all spaceborne or ground-based observations I am aware of. Such a model is not final but is useful in a heuristic way because it shows the constraints and difficulties in adjusting the elemental balance of all molecules to the total elemental ratios that have been established in a completely different way (see Delsemme 1982). Such a balance sheet for Comet Halley represents the first success in duplicating the elemental ratios given in Table 3 for comet gases.

To do so, the $\mathrm{O} / \mathrm{C}$ ratio must be boosted. The easiest way is to assume that unobserved formic acid is one of the parent molecules releasing $\mathrm{CO}$ in the 
Table 6. Chemical Composition of the Volatile Fraction of Comet Halley in Atom Numbers ${ }^{\mathrm{a}}$

BALANCE SHEET OF THE ELEMENTS

\section{PARENT MOLECULES}

\section{$\mathrm{H}$}

C

$\mathrm{O}$

$\mathrm{N}$

S

\section{0\% With O:}

$78.5 \% \mathrm{H}_{2} \mathrm{O}$
$4.5 \% \mathrm{HCO} \cdot \mathrm{OH}$
$4.0 \% \mathrm{H}_{2} \mathrm{CO}$
$3.5 \% \mathrm{CO}_{2}$
$1.5 \% \mathrm{CO}$

5.6\% With N:

$2.6 \% \mathrm{~N}_{2}$
$1.0 \% \mathrm{HCN}$
$0.8 \% \mathrm{NH}_{3}$
$0.8 \% \mathrm{~N}_{2} \mathrm{H}_{4}$
$0.4 \% \mathrm{C}_{4} \mathrm{H}_{4} \mathrm{~N}_{2}$

2.2\% Hvdrocarbons:

$$
\begin{gathered}
1.5 \% \mathrm{C}_{2} \mathrm{H}_{2} \\
0.5 \% \mathrm{CH}_{4} \\
0.2 \% \mathrm{C}_{3} \mathrm{H}_{2} \\
0.2 \% \text { With S: } \\
\hline 0.1 \% \mathrm{H}_{2} \mathrm{~S} \\
0.05 \% \mathrm{CS}_{2} \\
0.05 \% \mathrm{~S}_{2}
\end{gathered}
$$

Totals:

$$
\begin{array}{cc}
187.6 & 20.25 \\
\mathrm{H} / \mathrm{O}=1.876 & \mathrm{C} / \mathrm{O}=0.2025 \\
\mathrm{H} / \mathrm{O}=1.86 & \mathrm{C} / \mathrm{O}=0.2
\end{array}
$$

Elemental Ratios:

78.5
9
4
7
1.5

-.

$\begin{array}{ll}-- & 1.0\end{array}$

$\begin{array}{cc}- & \\ - & 0.8\end{array}$

$-\quad 1.6$

$\begin{array}{ll}-- & 0.8\end{array}$

$\begin{array}{ll}- & 0.1\end{array}$

$-$

$-$

0.1

$\begin{array}{lll}-- & - & 0.1\end{array}$

100.0

10.0

0.3

$\mathrm{N} / \mathrm{O}=0.10 \quad \mathrm{~S} / \mathrm{O}=0.003$

$\mathrm{N} / \mathrm{O}=0.10 \quad \mathrm{~S} / \mathrm{O}=0.003$

a The apparent accuracy of this balance sheet must not be taken at face value, because error bars are large. See text for further details. 
observed extended source of $\mathrm{CO}$ surrounding the nucleus. In Table 6, water also had to be brought down from $80 \%$ to $78 \%$ to make room for enough nitrogenbearing molecules, in order to reach a N/O ratio close to 0.1. Formic acid $(\mathrm{HCO} \cdot \mathrm{OH})$ and formaldehyde $\left(\mathrm{H}_{2} \mathrm{CO}\right)$ remain the major oxygen-bearing organic molecules and provide the extended source of $\mathrm{CO}$ by vaporizing from an icy-grain halo $20,000 \mathrm{~km}$ in radius. Their photodissociation by solar ultraviolet indeed occurs with a half-life shorter than the survival time of the icy grains, whereas the survival rate of the grains is consistent with the vapor pressures of $\mathrm{HCO} \cdot \mathrm{OH}$ and $\mathrm{H}_{2} \mathrm{CO}$. $\mathrm{CO}_{2}$ and $\mathrm{N}_{2}$ provide by photoionization and/or charge exchange the $\mathrm{CO}_{2}{ }^{+}$ and $\mathrm{N}_{2}{ }^{+}$ions observed in the plasma tails. The photodissociation of a fraction of $\mathrm{CO}_{2}$ also competes with the preexisting $\mathrm{CO}$, which provides the point-source of $\mathrm{CO}$ observed in Comet Halley (Eberhardt et al. 1987). $\mathrm{HCN}, \mathrm{C}_{2} \mathrm{H}_{2}$ and $\mathrm{C}_{3} \mathrm{H}_{2}$ are in the right proportions to explain the ratios of the production rates of $\mathrm{CN}, \mathrm{C}_{2}$ and $\mathrm{C}_{3}$, respectively (Cochran 1987). The $\mathrm{C}_{3} \mathrm{H}_{2}$ molecule, observed in interstellar space, is probably the cyclo-propenyl radical, whose cation $\mathrm{C}_{3} \mathrm{H}_{3}{ }^{+}$has been identified in the coma of Comet Halley by the positive ion cluster composition analyzer PICCA on the Giotto spacecraft (Korth et al. 1989).

I have written $0.4 \% \mathrm{C}_{4} \mathrm{H}_{4} \mathrm{~N}_{2}$ (pyrimidine) in the molecules with $\mathrm{N}$, mostly as a reminder that there are heterocyclics with $\mathrm{N}$ almost as volatile as water; pyrimidine is a good example since at atmospheric pressure it boils at $123^{\circ} \mathrm{C}$ and its melting point is $22^{\circ} \mathrm{C}$ (Weast et al. 1984). Several heterocyclics, including pyrimidine, have been identified in the CHON grains by Krueger and Kissel (1987).

Hydrogen cyanide is the source of $\mathrm{CN}$, as demonstrated by the energy balance of its photodissociation and the observed velocity of its molecular fragments (Combi and Delsemme 1980). Hydrazine $\mathrm{N}_{2} \mathrm{H}_{4}$, and not $\mathrm{HN}_{3}$, is the probable source of $\mathrm{NH}_{2}$ (Delsemme 1975). The large amount of $\mathrm{N}_{2}$ needed to balance the $\mathrm{N}$ budget also implies that $\mathrm{N}_{2}^{+}$has been considerably depleted in the onset of the tail, by dissociative recombination with electrons, assumedly because of the magnetic confinement of the plasma; besides, there might be more $\mathrm{N}$ bearing molecules yet undiscovered that could compensate for a smaller abundance of $\mathrm{N}_{2}$. The apparent accuracy of Table 6 must not be taken at face value, because other possible solutions could be found by using other elemental ratios still within the limits of their error bars. In particular, balancing the budget would be much easier if the H/O ratio could be somewhat larger than 2 .

\subsection{SILICATES IN CHONDRITES AND IN COMETS}

As demonstrated in Figure 2, the abundances of most elements in Comet Halley are close to chondritic abundances. This is true on the average, in spite of the fact that the sample of 79 grains displayed a surprising chemical diversity. Two major exceptions are visible in Figure 2. Silicon and iron are each a factor of two off the diagonal line, but in opposite directions; hence the nominal $\mathrm{Fe} / \mathrm{Si}$ ratio is only $25 \%$ solar in Comet Halley. 
It is, of course, possible that the $\mathrm{Fe} / \mathrm{Si}$ ratio is entirely spurious, because of systematic errors, due to the fast flyby, that are not completely understood. However, these errors do not seem to affect the other elements so much, since the average of the 79 grains is surprisingly close to the chondritic values. Statistical fluctuations are also always possible on a small sample, but a factor of 4 is extremely unlikely for a sample that shows such a good average homogeneity for all other elements.

The $\mathrm{Fe} / \mathrm{Si}$ ratio is very important because $\mathrm{Fe}$ and $\mathrm{Si}$ are the two major metals that, with $\mathrm{Mg}$, make the bulk of the silicates in chondrites. The $\mathrm{Fe} / \mathrm{Si}$ ratio is, of course, more accurately known in chondrites than in comets; surprisingly, it also shows a variable depletion from $75 \%$ solar to $25 \%$ solar. Modern values are used here to establish these ratios: in particular, the revised values for the abundances of iron and silicon in the Sun were carefully discussed by Grevesse (1984a, 1984b), updated by Anders and Grevesse (1989) and used in Table 1.

$\mathrm{The} \mathrm{Fe} / \mathrm{Si}$ ratio has played an important role in the classification of chondrites, as well as their differences in oxidation state (Urey and Craig 1953). Figure 4 represents a Urey-Craig diagram in which I have plotted the positions of the different groups of chondrites by dispersion ellipses imprisoning the cluster of points. To identify these clusters, I have used data from Larimer and Wasson (1988). The letters in the figure are identified in Table 7.

Figure 4 shows the location of Comet Halley's dust: it occupies the whole $45^{\circ}$ line corresponding to $\mathrm{Fe} / \mathrm{Si}=25 \%$ solar. The scatter of each individual grain would even be much larger if they were plotted separately. This is also partially true if each constituent mineral were plotted for each chondrite, but the scatter would be much smaller (Larimer and Wasson 1988) than for cometary dust.

Figure 4 also shows the position of the Earth on a Urey-Craig diagram, if its matter were homogenized. The horizontal spread of the line comes from the uncertainty of the iron content for the mantle silicates. The position of the Earth is shown here to remind us that $3 / 4$ of the Earth's iron is in its reduced metallic core and $1 / 4$ only in its oxidized mantle, a fact that any theory of the origin of the terrestrial planets must explain.

The interpretation of the abundance patterns in the different groups of meteorites is usually explained in terms of a fractionation of a unique primitive mixture, although it is a basically unresolved problem. Most authors consider the $\mathrm{CI}$ chondrites to be representative of the primitive mixture, but the careful revision of the solar Fe/Si ratio, now $1.30 \pm 0.26$ (Grevesse 1984a, 1984b, Anders and Grevesse 1989), makes it very doubtful that CI chondrites could represent unfractionated material close to solar composition.

The fractionation and depletion of iron in all carbonaceous chondrites imply that they are not as primitive as we would like to believe, and they may have been partially homogenized by the same processes that have produced their fractionation. The very large heterogeneity of the cometary grains, combined with the fact that they are yet chondritic in bulk, implies that they are extremely primitive. This cannot be reconciled with a bulk depletion of iron. We conclude this discussion by submitting that if the $\mathrm{Fe} / \mathrm{Si}=25 \%$ solar ratio is not an artifact 


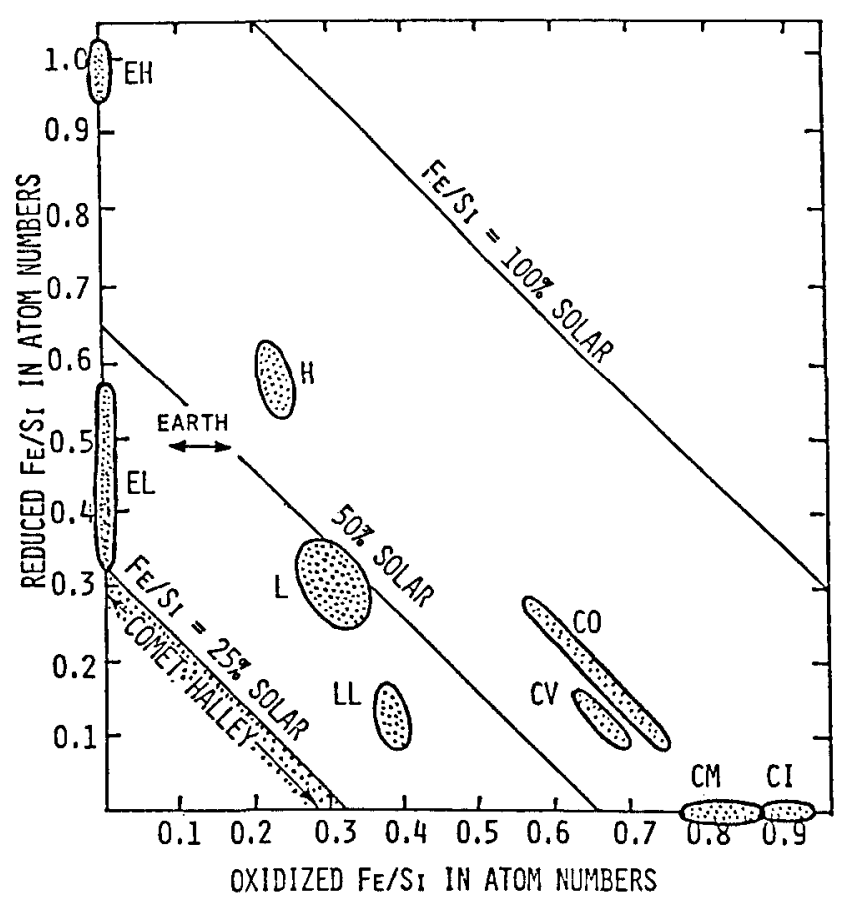

Figure 4. Urey-Craig diagram of the distribution of reduced versus oxidized iron in all chondrites. The chondrite clusters are from recent data given by Larimer and Wasson (1988). The $45^{\circ}$ slopes are for constant $\mathrm{Fe} / \mathrm{Si}$ ratios. The solar ratio of $\mathrm{Fe} / \mathrm{Si}=1.3$, from Table 1 (Anders and Grevesse 1989). The Comet Halley data are from this paper: the comet's dust grains go from completely reduced to completely oxidized; the anomalous $\mathrm{Fe} / \mathrm{Si}$ ratio of $0.25 \%$ of the solar ratio must be viewed with caution because it comes from the mean of 79 microscopic grains showing a wide chemical diversity. Finally, the horizontal line with two arrows represents the composition of the Earth (which is assumed to be homogenized). The arrows show the uncertainty of the iron content of the mantle silicates: the left extremity is for a chondritic mantle throughout, and the right one is for a lower mantle considerably enriched in iron. 
Table 7. Urey-Craig Classification of Chondrites (see Figure 4) ${ }^{\mathrm{a}}$

1. Carbonaceous chondrites (completely oxidized)

CI (C I old style): Fe/Si near 0.90

CM (C II old style): Fe/Si near 0.80

2. Carbonaceous chondrites (not completely oxidized)

$\mathrm{CO}$ (C III old style): $\mathrm{Fe} / \mathrm{Si}$ near 0.85

CV (C III old style): Fe/Si near 0.80

3. Ordinary chondrites (somewhat oxidized)

$\mathrm{H}$ : High Fe/Si near 0.80

L: Low Fe/Si near 0.55

LL: Very low Fe/Si near 0.45

4. Enstatite chondrites (completely reduced)

EH: High Fe/Si near 1.0

EL: Low Fe/Si near 0.4-0.5

a Note: The Fe/Si ratio in the Sun is $1.30 \pm 0.26$.

of the measurements, its significance may be important, but its meaning is not understood.

\subsection{ORGANIC MATTER IN CHONDRITES AND IN COMETS}

The major difference between cometary dust and chondrites lies in the dust's total carbon content. Cometary dust is close to $25 \%$ carbon by weight, whereas the highest amount of carbon in chondrites is lower by almost one order of magnitude: $1 \%$ to $3 \%$ carbon in $\mathrm{CM}$ chondrites, and $3 \%$ to $5 \%$ in $\mathrm{CI}$ chondrites.

In carbonaceous chondrites, $2 / 3$ to $3 / 4$ of this carbon is present as an insoluble macromolecular compound containing $\mathrm{C}, \mathrm{H}, \mathrm{O}, \mathrm{N}$, and $\mathrm{S}$ (Cronin et al. 1988). In Comet Halley, Kissel and Krueger (1987) report the existence of a thick mantle of organic refractory material covering the cores of many silicate grains, and containing mainly $\mathrm{C}, \mathrm{H}, \mathrm{O}$, and $\mathrm{N}$. There are also grains of pure $\mathrm{CHON}$ material without silicate cores. This CHON is also likely to be mostly a macromolecular organic compound. Kissel and Krueger report that it is rather fluffy (the density is between 0.2 and $1.0 \mathrm{~g} / \mathrm{cm}^{3}$ ). Therefore its pores could have 
contained in a condensed form the water and the organic gases detected in the cometary atmosphere. This organic polymer compound is likely to be heterogeneous in both cases; it has been difficult to characterize in chondrites because of its insolubility, whereas the rest of the organic matter has been abundantly studied, mostly in CM chondrites, in particular thanks to the CM chondrite fall near Murchinson (Australia) in 1969.

A grand total of 411 different compounds have been identified in the soluble organic fraction of CM chondrites (Cronin et al. 1988): in particular, 44 different carboxylic acids (total amount $350 \mathrm{ppm}$ ), 227 aliphatic and aromatic hydrocarbons (60 ppm), 74 amino-acids $(60 \mathrm{ppm}), 12$ amines and amides (60 ppm), 17 alcohols, aldehydes and ketones (40 ppm), 32 heterocyclics with $\mathrm{N}$ ( $7 \mathrm{ppm}), 4$ purines (adenine, guanine, xanthine and hypoxanthine) and 1 pyrimidine (uracil). All the purines and the pyrimidine were found near the $1 \mathrm{ppm}$ level and are common in biological systems. As far as the amino-acids are concerned, 8 are used in proteins (glycine, alanine, valine, leucine, isoleucine, proline, aspartic acid, and glutamic acid) and 11 more are used in less common biological systems. The remaining 55 amino-acids do not have any present connection with biology (Cronin et al. 1988).

In the dust grains of Comet Halley, Kissel and Krueger (1987) have also detected or deduced the presence of a very large number of organic compounds. Because of the nature of the identifications, which use, for instance, several pairs of coincidences in mass spectra of molecular fragments, the identification of specific compounds is less certain than the general nature of compound families, whose existence is rather well established. These families are:

1. Unsaturated hydrocarbons (pentyne, hexyne, butadiene, pentadiene, cyclopentene, cyclohexadiene, cyclohexene, cyclohexadiene, benzene, and toluene).

2. Nitrogen derivatives (hydrocyanic acid, acetonitrile, propanonitrile, iminomethane, aminoethylene, and iminopropene).

3. Heterocyclics with nitrogen (pyrroline, pyrrole, imidazole, pyridine, pyrimidine, purine, and adenine).

4. Oxy-heterocyclics with nitrogen (oximidazole, oxypyrimidine, and xanthine).

5. Aldehydes and acids (formaldehyde, acetaldehyde, and formic and acetic acids).

6. amino-, imino-, nitrile of -ole, -ale, -keto, etc. (probable).

Although quite remarkable, the previous results of the time-of-flight mass spectrometer PUMA on board VEGA 1, during the few crucial minutes of the Halley flyby, cannot be compared with the wealth of information that has been accumulated in a few decades of patient work by meteoriticists; in particular, because of the excessive impact velocity of the grains, it would have been useless to have a gas chromatograph on board to complement the mass spectrometer results. 
In spite of all the uncertainties, the many similitudes between the organic compounds in chondrites and in the dust of Comet Halley are consistent with the paradigm that we will describe later. That the biologically significant heterocyclics (purines and pyrimidines) are also likely to be present in comets, whereas aminoacids were undetected, is a fact whose significance is not understood. Only gas chromatography combined with mass spectroscopy in a rendezvous mission of the Comet Rendezvous Asteroid Flyby (CRAF) type could improve our knowledge enough to bring some clarification in this respect.

\section{Organic Compounds in Interstellar Space}

\subsection{INTERSTELLAR MOLECULES IN THE GAS PHASE}

The first interstellar lines of molecular radicals and ions had already been identified by spectroscopy in the visual before the 1940s. They came from the transitions of the lowest rotational levels of diatomic molecules: of $\mathrm{CH}$ (Swings and Rosenfeld 1937), of CN and of $\mathrm{CH}^{+}$(McKellar 1940, Douglas and Herzberg 1941). With the development of radio astronomy, the identification of new interstellar molecules took off slowly. In 1969 , only $\mathrm{OH}, \mathrm{H}_{2} \mathrm{O}$ and $\mathrm{H}_{2} \mathrm{CO}$ (formaldehyde) had been identified, but 18 more molecules were found in 1970-71 and 39 molecules were known in 1975 (Herbst and Klemperer 1976). Finally, 80 interstellar molecules had been identified by 1988 (Irvine and Knacke 1988), with 61 of them being organic and only 19 inorganic. The list of interstellar molecules is given in Tables 8 and 9.

A quantitative theory for the formation of polyatomic molecules in interstellar clouds slowly emerged in the 1970s (Herbst and Klemperer 1976). Quantitative predictions are confronted with two obstacles: the lack of rate constants for many ion-molecule reactions, and the lack of thermodynamic data for polyatomic ions. Otherwise, the basic formation mechanisms seem to be understood: the interstellar chemistry depends on chemical kinetics, the results are far away from equilibrium, and entropy does not play any role because of the nearness of absolute zero. All reactions are exothermic, and gas density is too small to have triple collisions ever, except in collisions with grains. Finally, the source of energy is the ionization due to the ultraviolet light of stars, which produces cascades of fast ion-molecular reactions starting from the most abundant ions $\mathrm{H}^{+}$and $\mathrm{He}^{+}$.

\subsection{INTERSTELLAR DUST}

The nature of interstellar dust is more difficult to establish. However, the existence of dust in interstellar space seems to be mainly due to the transfer from stars to space of those heavier elements that have been synthesized in stellar cores by thermonuclear reactions. Although many details of this transfer (e.g., stellar winds, planetary nebulae, and explosions from novas and supernovas) are not yet 
Table 8. Identified Interstellar Molecules ${ }^{\mathrm{a}}$

INORGANIC:

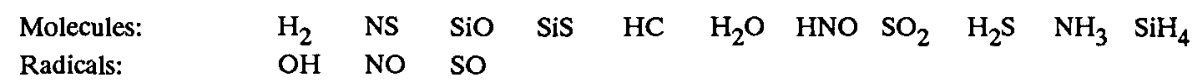

\section{ORGANIC:}

\begin{tabular}{|c|c|c|c|c|c|c|}
\hline \multirow{2}{*}{$\begin{array}{l}\text { Hydrocarbons: } \\
\text { Radicals: }\end{array}$} & \multirow{2}{*}{$\begin{array}{l}\mathrm{CH}_{4} \\
\mathrm{C}_{2} \mathrm{H}\end{array}$} & $\mathrm{C}_{2} \mathrm{H}_{2}$ & $\mathrm{C}_{2} \mathrm{H}_{4}$ & $\mathrm{CH}_{3}-\mathrm{C}=\mathrm{CH}$ & \multicolumn{2}{|c|}{$\mathrm{CH}_{3}-(\mathrm{C}=\mathrm{C})_{2}-\mathrm{H}$} \\
\hline & & $\mathrm{C}_{3} \mathrm{H} \quad \mathrm{C}_{4} \mathrm{H}$ & $\mathrm{C}_{5} \mathrm{H} \quad \mathrm{C}_{6} \mathrm{H}$ & $c_{2}$ & $\mathrm{C}_{3} \mathrm{H}$ & cyclo $\mathrm{C}_{3} \mathrm{H}_{2}$ \\
\hline \multirow[t]{2}{*}{ Cyanides: } & $\mathrm{HCN}$ & $\mathrm{CH}_{3} \mathrm{CN}$ & $\mathrm{CH}_{3}-\mathrm{CH}_{2}-\mathrm{CN}$ & $\mathrm{CH}_{2}=\mathrm{CH}$ & $\mathrm{CH}_{3}-\mathrm{C}=\mathrm{C}-\mathrm{CN}$ & $\mathrm{CH}_{3}-(\mathrm{C}=\mathrm{C})_{2}$ \\
\hline & $\mathrm{CN}$ & $\mathrm{C} \equiv \mathrm{C}-\mathrm{CN}$ & $\mathrm{H}(\mathrm{C}=\mathrm{C}) \mathrm{n}-\mathrm{CN}$ & with $n=c$ & $2,3,4,5$ & $\mathrm{HN}=\mathrm{C}$ \\
\hline \multirow[t]{2}{*}{ With O: } & $\mathrm{CO}$ & $\mathrm{CH}_{2}=0$ & $\mathrm{CH}_{3}-\mathrm{CH}=0$ & $\mathrm{CH}_{3}-\mathrm{OH}$ & $\mathrm{CH}_{3}-\mathrm{CH}_{2}-\mathrm{OH}$ & $\mathrm{CH}_{3}-\mathrm{CO}-\mathrm{CH}_{3}$ \\
\hline & $\begin{array}{l}\mathrm{H}-\mathrm{CC} \\
\mathrm{HC}=\end{array}$ & $\begin{array}{l}\mathrm{CH}_{3}- \\
\mathrm{HCO}\end{array}$ & $\mathrm{O}-\mathrm{CH}_{3} \quad \mathrm{CH}_{3}-$ & $-\mathrm{CO}-\mathrm{H}$ & $\mathrm{O}=\mathrm{C}=\mathrm{CH}_{2}$ & $\mathrm{C}=\mathrm{C}-\mathrm{CO}$ \\
\hline
\end{tabular}

With $\mathrm{NH}_{2}: \quad \mathrm{NH}_{2}-\mathrm{CO}-\mathrm{H} \quad \mathrm{NH}_{2}-\mathrm{CH}_{3} \quad \mathrm{NH}_{2}-\mathrm{CN} \quad$ with $\mathrm{NH}: \quad \mathrm{NH}=\mathrm{CH}_{2} \quad \mathrm{NH}=\mathrm{CO}$

With S: $\quad \mathrm{S}=\mathrm{CH}_{2} \mathrm{SH}-\mathrm{CH}_{3} \quad \mathrm{~S}=\mathrm{C}=\mathrm{NH} \quad \mathrm{C}=\mathrm{C}-\mathrm{CS} \quad \mathrm{OCS} \quad \mathrm{C}_{2} \quad \mathrm{HSCC}$

With Si: $\quad \mathrm{SiC}_{2} \quad \mathrm{HSiCC}$ ?

IONS:

$\begin{array}{lllll}\text { Organic: } & \mathrm{CH}+\mathrm{HCO}+ & \mathrm{OH}-\mathrm{CO}+\mathrm{CH}-\mathrm{NH}+\mathrm{HCS}+\text { HOC+? } \\ \text { Inorganic: } & \mathrm{NH}_{2}+\mathrm{SO}+ & \mathrm{H}_{3} \mathrm{O}+\quad \mathrm{H}_{2} \mathrm{D}+?\end{array}$

a Data rearranged from Irvine and Knacke (1988). 
Table 9. Interstellar Molecules Whose Abundance Cannot Be Measured by Radio Astronomical Techniques

1. Undetectable Molecules

$\begin{array}{lllllll}\mathrm{H}_{2} & \mathrm{~N}_{2} & \mathrm{O}_{2} & \mathrm{CH}_{4} & \mathrm{CO}_{2} & \text { have no electric dipole moment because }\end{array}$ they have a center of symmetry.

However, indirect data give some indications:

$\mathrm{CO} / \mathrm{H} 2=1.2 \times 10^{-4} \quad$ From CO absorption band in IR (Watson 1984) Consistent with $>0.8 \times 10^{-4}$ (Black et al. 1984).

$\mathrm{CH}_{4} / \mathrm{CO}<10^{-2} \quad \mathrm{CH}_{4}$ undetected in IR (Knacke et al. 1985).

$\mathrm{CO}_{2} / \mathrm{CO}<<1 \quad$ From observed $\mathrm{HCO}_{2}{ }^{+}$and ionization model (Irvine and Knacke 1988).

$\mathrm{O}_{2} / \mathrm{CO}<1 \quad 16 \mathrm{O} / 18 \mathrm{O}$ undetected (Goldsmith et al. 1985).

\section{H2O Abundance Cannot Be Measured}

( $\mathrm{H}_{2} \mathrm{O}$ is excited by maser action; amplification unknown)
$\mathrm{H}_{2} \mathrm{O} / \mathrm{CO} \sim 1$
From HDO and fractionation model (Olofsson 1984).
$\mathrm{H}_{2} \mathrm{O} / \mathrm{CO}<1$
From cosmic abundances and carbon sink in grains. 
completely understood, the interstellar dust grains probably originate mostly in the hot gas flowing out from stars, because a fraction of this gas condenses into solid grains as it cools.

It is to be expected that silicate grains will appear in the stellar winds of oxygen-rich stars, whereas carbonaceous grains will come from carbon-rich stars. Indeed, a number of oxygen-rich red giant and supergiant stars whose mass loss rates are known show a circumstellar dust cloud with the silicate feature at $9.7 \mu \mathrm{m}$ in their infrared spectra, directly proportional to the gas ejection rate (Skinner and Whitmore 1988). In the same way, the IRAS survey of 304 cool carbon stars shows the infrared emission of expanding dust shells (Willems and de Jong 1988), and these dust shells contain mostly amorphous carbon grains on the order of $0.1 \mu \mathrm{m}$ (Orofino et al. 1987, Martin and Rogers 1987). The formation of these grains seems to be best described by a chemical pathway from the acetylene molecule, through polyaromatic hydrocarbons (Sedlmayr 1987) that are basically similar to the polycyclic aromatic hydrocarbons (PAH) described later. Finally, the proportion of carbon-rich to oxygen-rich giants is $60 \%$ in the IRAS survey (Baron et al. 1987); this ratio gives at least a crude indication of the possible proportion of the carbonaceous to siliceous dust flowing out from stars to the interstellar medium.

The interstellar dust has features that rather support this view. In diffuse interstellar clouds, the infrared emission bands of silicates imply that the silicaceous grains constitute about $50 \%$ of the total. On the other hand, the major metals like $\mathrm{Fe}, \mathrm{Mg}$, and $\mathrm{Si}$ are strongly depleted in the gas phase of the interstellar medium (see Table 10). The missing fraction is likely to be hidden in silicate grains. However, silicates can only account for a small fraction of the observed extinction curve (Greenberg 1974). In order to duplicate the observed extinction, about two-thirds of the cosmic abundance of carbon should be put in solid grains; this is consistent with the fact that, along many lines of sight--although not always--only one-third of the cosmic abundance of carbon is detected in the gas phase (Jenkins et al. 1983); see also Table 10. Nitrogen and oxygen might also be somewhat depleted in the gas phase, but much less than carbon (York et al. 1983), although the error bars are large. Oxygen is more abundant than metals; therefore only a small depletion of oxygen is required to make the proper amount of silicates.

The existence of grains containing carbonaceous material is supported by the interpretation of the wide interstellar band at $2175 \AA \pm 30 \AA$. Leger and Puget (1984) have proposed a mixture of different types of polycyclic aromatic hydrocarbons (PAH) that looks very much like the ill-defined insoluble carbonaceous residue observed in carbonaceous chondrites. The evidence remains inconclusive because the interstellar band features are not specific enough. At any rate, the graphite-silicate model (Mathis et al. 1977) seems to remain consistent with all available evidence (Draine and Lee 1984), if we accept that "graphite" could really be a semi-amorphous carbonaceous material (Sakata et al. 1983).

Hong and Greenberg (1980) propose a somewhat different model, in which a population of fine graphite grains (explaining the $2200-\AA$ bump in the extinction 
Table 10. Elemental Depletions in Interstellar Gas á

\begin{tabular}{llllll}
\hline ELEMENT & $\begin{array}{l}\text { LOG N IN } \\
\text { I.S. }{ }^{b} \text { GAS }\end{array}$ & $\begin{array}{l}\text { LOG I.S. } \\
\text { DEPLETION }\end{array}$ & ELEMENT & $\begin{array}{l}\text { LOG N IN } \\
\text { I.S. GAS }\end{array}$ & $\begin{array}{l}\text { LOG I.S. } \\
\text { DEPLETION }\end{array}$ \\
\hline & & & & & \\
$\mathrm{C}$ & 8.28 & -0.28 & $\mathrm{~S}$ & 7.01 & -0.20 \\
$\mathrm{~N}$ & 7.9 & -0.15 & $\mathrm{~K}$ & 3.2 & -1.92 \\
$\mathrm{O}$ & 8.7 & -0.23 & $\mathrm{Ca}$ & 3.6 & -2.76 \\
$\mathrm{Mg}$ & 6.99 & -0.59 & $\mathrm{Mn}$ & 4.21 & -1.18 \\
$\mathrm{Al}$ & 4.55 & -1.97 & $\mathrm{Fe}$ & 5.54 & -2.13 \\
$\mathrm{Si}$ & 6.2 & -1.35 & $\mathrm{Ni}$ & 4.26 & -1.99 \\
\hline
\end{tabular}

Averages in cold interstellar gas from Cowie and Songaila (1986). Depletions computed from Anders and Grevesse (1989) data (Table 1).

curve) is added to a population of grains with silicate cores covered by a refractory mantle of organic material--rather similar to cometary grains. In this model, the bulk of the extinction in the visual is due to the core-mantle grains. This interpretation is supported by the laboratory experiments of Greenberg et al. (1983): using ultraviolet irradiation, they converted ices of $\mathrm{H}_{2} \mathrm{O}, \mathrm{CO}, \mathrm{CH}_{4}$ and $\mathrm{NH}_{3}$ into a complex organic material.

\subsection{GRAIN GROWTH IN DENSE MOLECULAR CLOUDS}

We must turn now to the dense molecular clouds, because of their importance in star formation. Physical processes act to change the composition of molecules and grains in dense clouds. In diffuse clouds, photodissociation by the ultraviolet light coming from outside stars limits the size of the end products of the ion-molecular reactions, and the temperature remains larger than, let us say, $50 \mathrm{~K}$, whereas in dense clouds, starlight does not penetrate deeply, so the cloud cools off; its molecules can radiate down to very low temperatures because they have closely spaced rotational levels close to their ground state. As an example, the abundant $\mathrm{CO}$ molecule emits a $2.6-\mathrm{mm}$ photon by the $\mathrm{J}=1$ to 0 transition; hence it can cool down to $5 \mathrm{~K}$ very easily, or at least to 10 or $15 \mathrm{~K}$ if there is a collisional steady state with other molecules.

Anomalous extinction curves show the existence of grain growth in dark clouds. Lines of sight through dense clouds often show an absorption feature at $3.1 \mu \mathrm{m}$, usually attributed to water ice (Leger et al. 1983). At the very low temperatures of clouds, accretion of ice mantles seems the most plausible 
explanation. The interpretation of water ice has been confirmed by the detection of a second $\mathrm{H}_{2} \mathrm{O}$ ice band at $6.0 \mu \mathrm{m}$ (Willner et al. 1982). Of course, many of the interstellar molecules of Tables 8 and 9 can and will condense at this low temperature, with the most abundant of these molecules being $\mathrm{CO}$, and then $\mathrm{H}_{2} \mathrm{O}$, $\mathrm{HCN}, \mathrm{NH}_{3}$, and $\mathrm{H}_{2} \mathrm{CO}$. Other infrared features have been observed: for instance, an absorption band at $2.97 \mu \mathrm{m}$, which could come from a solid mixture of $\mathrm{NH}_{3}$ and $\mathrm{H}_{2} \mathrm{O}$ (Knacke et al. 1982); a C-H stretching vibration in hydrocarbons at $3.4 \mu \mathrm{m}$ (Jones et al. 1983); a $4.67 \mu \mathrm{m}$ band due to solid CO (Lacy et al. 1984); and also other unidentified bands.

To summarize, there must exist a large variety of grains in interstellar space, if we judge from their origins. Metallic oxides condense in stellar winds from oxygen-rich stars; abundant $\mathrm{Fe}, \mathrm{Mg}$, and $\mathrm{Si}$ oxides combine to make silicates, whereas less abundant $\mathrm{Ca}$ and $\mathrm{Al}$ oxides had already condensed at a higher temperature (hence earlier) to make refractory oxide grains. Oxides cannot form in carbon-rich stars; only $\mathrm{SiC}$ (Cernicharo et al. 1989), amorphous carbon or carbonaceous grains will condense, with the possibility of tiny crystal structures like fullerenes (Kroto 1988), graphite or even diamond (Lewis et al. 1987).

\subsection{GRAINS WITH ICY MANTLES IN MOLECULAR CLOUDS}

Most of these grains may survive in dense molecular clouds. Some must survive as such, since there is evidence of extremely fine grains. However, a significant fraction is going to become the cores of larger grains covered by an organic mantle. During the cooling of dark clouds, these cores became the nucleation centers for water ice and organic molecules of the types seen (Table 8) or suspected (Table 9) in the gas phase of the interstellar medium. The condensation sequence is easy to establish from the vapor pressures of the different constituents. For instance, because of their larger volatility, neither $\mathrm{CO}$ nor $\mathrm{CH}_{4}$ will condense except at the lowest temperatures; hence the amount of $\mathrm{CO}$ and $\mathrm{CH}_{4}$ will remain very low in the condensed mantles.

These mantles will be processed in different ways, depending on the temperature history of the cloud. First, the ultraviolet light of the nearby stars will produce those changes studied in the laboratory and described by Greenberg (1982). Later, when the cloud has become too opaque for the ultraviolet light to reach the grains, mantle processing will continue at a slower rate, thanks to the galactic cosmic rays (Strazzula et al. 1983, Pirronello 1988). The gross result of this processing is to free mostly $\mathrm{H}$ atoms and induce the appearance of radicals as well as of unsaturated molecules that polymerize readily, producing the same type of refractory CHON polymer described by Greenberg. This effect has also been recognized as playing a role in the upper surface layers of comets (Whipple 1977, Draganic and Draganic 1984). 
Table 11. Molecules in Giant Interstellar Clouds ${ }^{\mathrm{a}}$

\begin{tabular}{llll}
\hline MOLECULE & LOG $\mathrm{N}$ & MOLECULE & LOG N \\
\hline $\mathrm{H}_{2}$ & 12 & $\mathrm{NH}_{3}$ & 5 \\
$\mathrm{CO}$ & 8 & $\mathrm{HCN}$ & 5 \\
$\mathrm{H}_{2} \mathrm{O}$ & $7 ?$ & $\mathrm{CH}_{4}$ & $5 ?$ \\
$\mathrm{CO}_{2}$ & $6 ?$ & $\mathrm{CH}_{3}-\mathrm{O}_{-} \mathrm{CH}_{3}$ & 5 \\
$\mathrm{CH}_{3} \mathrm{OH}$ & $5-6$ & $\mathrm{CS}$ & $4-5$ \\
$\mathrm{H}_{2} \mathrm{CO}$ & $5-6$ & $\mathrm{SO}$ & 4 \\
$\mathrm{~N}_{2}$ & $5-6 ?$ & $\mathrm{SO}$ & 4 \\
\hline
\end{tabular}

a Abundances of selected species, summarized from Irvine et al. (1985). Uncertainties are large. Question marks indicate educated guesses.

\subsection{A MODEL FOR THE GRAINS WITH ICY MANTLES}

To understand the quantitative composition of the organic mantles that could condense on the interstellar grains, Table 11 gives the crude abundances of a few selected molecules available in the gas phase. Table 11 is deduced from Irvine et al. (1985) and from Irvine and Knacke (1988); it is not meant as a substitute for their careful discussion.

At temperatures higher than $30 \mathrm{~K}$, only a very small fraction of $\mathrm{H}_{2}, \mathrm{~N}_{2}, \mathrm{CO}$ and $\mathrm{CH}_{4}$ would condense on grains, because of the very high vapor pressure of these molecules, whereas practically the total amount of all other molecules of Table 11 would. A minor adsorption of volatile molecules on amorphous ice is, however, possible, preparing the road for clathrate hydrates at higher temperatures (Delsemme and Miller 1970).

The condensed mantle would therefore be composed approximately of $80 \%$ water ice, $15 \%\left(\mathrm{CO}+\mathrm{CO}_{2}+\mathrm{CH}_{3} \mathrm{OH}+\mathrm{H}_{2} \mathrm{CO}\right)$ and $5 \%$ of $\left(\mathrm{N}_{2}+\mathrm{NH}_{3}+\right.$ $\mathrm{HCN}+\mathrm{CH}_{4}+\mathrm{CH}_{3}-\mathrm{O}-\mathrm{CH}_{3}+\mathrm{CS}$ ), plus of course, many more molecules at the $0.1 \%$ to $0.01 \%$ level.

A fraction of these molecules would then be transformed slowly by the ultraviolet light of the nearby stars (or by the ionization of the cosmic rays if the cloud has become too opaque to starlight) into a complicated mixture of refractory organic polymers and radicals, as described by Greenberg (1982). Table 12 gives a comparison of Greenberg's predictions with the actual results 
Table 12. A Comparison of Comet Halley and Interstellar Grains With Icy Mantles

COMPOSITION

INTERSTELLAR GRAINS

(IN MASS FRACTION)

GREENBERG (1982)

COMET HALLEY

(THIS WORK)

$\begin{array}{lllll}\text { Silicates } & 0.21 & & 0.25 & \\ \text { Graphite } & 0.06 & & 0.02 & \\ \text { FeS + S } & --- & & 0.03 & \\ \text { Refractory organics } & \underline{0.19} & \underline{0.14} & \\ \quad \text { Sum, refractory fraction: } & & 0.46 & & 0.44 \\ \quad & & & 0.11 & \\ \text { Volatile organics } & 0.35 & & \underline{0.45} & \\ \text { Water } & \underline{0.19} & & & 0.56 \\ \quad \text { Sum, volatile fraction: } & & 0.54 & & 0.80\end{array}$

derived from Comet Halley's observations. In spite of all the uncertainties in the building up of Greenberg's model, the analogy is obvious. To understand the reasons for this analogy, it is time to consider the thermal history of the interstellar grains during the formation stages of the Solar System.

\section{Origin and History of Organic Compounds in Chondrites and Comets}

\subsection{STAR FORMATION IN MOLECULAR CLOUDS}

Molecular clouds are composed of clumps of high density. This was demonstrated by high resolution isophote maps in the radio wavelengths of several interstellar molecules, such as $\mathrm{H}_{2} \mathrm{CO}$ emissions (Evans and Kutner 1976), $\mathrm{HC}_{3} \mathrm{~N}$ (Avery 1980), and CS (Linke and Goldsmith 1980); these maps show very high intensity cores in the clumps. The densest observed cores seem to have sizes on the order of 0.1 parsec only and masses of one or two solar masses (reviewed by Shu et al. 1987). For such sizes and masses, a gravitational collapse to the core center can be stopped only by internal gas turbulence or by magnetic pressure; hence either turbulence damping or the escape of magnetic lines from the core could induce the collapse. A core actually undergoing collapse has been observed in a giant molecular cloud, W $49 \mathrm{~A}$ (Welch et al. 1987). Such observations are 
rare because the lifetime of a cloud is probably at least $10^{7}$ years, which is much longer than the $10^{5}$-year duration of a collapse.

Reviewing star formation in molecular clouds, Shu et al. (1987) distinguish five consecutive stages, summarized here:

1. Leakage of the magnetic and turbulent support of the clump core, possibly by ambipolar diffusion (Mestel and Spitzer 1956).

2. Dynamic collapse of the clump from the inside out, into a central protostar and a surrounding accretion disk, deeply embedded within an infalling envelope of dust and gas (Shu 1977).

3. Deuterium ignites thermonuclear reactions in the protostar, which, for small masses $\left(\mathrm{M}<2 \mathrm{M}_{\odot}\right.$ ), becomes completely convective and induces a bipolar stellar wind, while infalling matter slows down (Lada 1985).

4. Infalling matter subsides and stops, while the bipolar stellar wind opens its two cones and sweeps the gas remnants. A T Tauri star surrounded by a dusty disk has become observable (Adams and Shu 1985, 1986).

5. The gas remnants have been completely dissipated, and the dust disk has been incorporated into planets. A "naked" T Tauri star is observed (Walter 1986).

The formation of a viscous accretion disk surrounding and feeding the growing protostar seems to be the way Nature has found to get rid of the very large excess of angular momentum likely to be present in the molecular cloud clump undergoing collapse. Adjacent rotating zones moving at different (quasiKeplerian) velocities dissipate energy by viscous friction. The inner zones are slowed down, flow inwards, and feed the central star, while the outer zones are accelerated and flow outwards, carrying away the excess of angular momentum.

The basic theory of the viscous accretion disk was given by Lynden-Bell and Pringle (1974). The observational evidence has recently established the ubiquity of accretion disks around very young stars. The Infrared Astronomical Satellite (IRAS), surveying the existence of infrared sources near the 100-micrometer wavelength, has found many stars with a large infrared excess, the signature of circumstellar dust (Rowan-Robinson 1985). Many of these stars are very young $\mathrm{T}$ Tauri stars. Some, like FU Orionis, are still probably accreting mass (Hartmann and Kenyon 1985). Finally, optical pictures in the visual have resolved dusty disks between 500 and $1000 \mathrm{AU}$ in size, as in Beta Pictoris (Smith and Terrile 1984). Bipolar outflows are often present simultaneously (Harvey 1985).

Although there are yet many things to be learned about star formation, there is now strong evidence that many young stars, in particular those of the $\mathrm{T}$ Tauri type, are surrounded by accretion disks of the kind needed to produce planets. It is therefore reasonable to use the theory of viscous accretion disks to describe the "solar nebula" that has produced our Solar System. 


\subsection{GRAIN HISTORY DURING CLOUD COLLAPSE}

\subsubsection{Grain Clumping. During the free-fall collapse of the interstellar cloud} fragment, grains collide because they are dragged by gas eddies. There appears to be a hierarchy of grain accumulation that depends on the sticking factor of the grains. Cameron (1975) predicts a substantial number of millimeter- to centimeter-sized clumps that will help explain chondrules. Morfill et al. (1978) and Clayton (1980) also discuss the clumping of grains.

5.2.2. Grain Heating. The luminosity of an accreting protostar is essentially limited by the rate of release of its gravitational energy of collapse, which is: $\mathrm{L}=\mathrm{GMM} / \mathrm{R}$ where $\mathrm{M}$ is the mass already accreted, $\mathrm{M}$ is the mass accretion rate, and $R$ is the distance of the accretion shock to the center. Near the end of the collapse of one solar mass at the rate of $\mathrm{M}=10^{-5} \mathrm{M}_{\odot} / \mathrm{yr}$, a grain stopped in the disk reaches $40 \mathrm{~K}$ at $50 \mathrm{AU}, 150 \mathrm{~K}$ at $10 \mathrm{AU}, 300 \mathrm{~K}$ at $5 \mathrm{AU}$ and $1500 \mathrm{~K}$ at $1 \mathrm{AU}$ (Adams and Shu 1985). In other words, all grains except possibly graphite and other refractory grains vaporize at $1 \mathrm{AU}$; organic mantles will be lost near $3 \mathrm{AU}$ and water itself at $4 \mathrm{AU}$. Only if the mass accretion rate itself subsides very much near the end of the infall would the last infalling grains survive at closer distances from the protosun. This is a simpleminded approach that is considerably improved by models of the accretion disk, but the source of heat remains the same.

5.2.3. Penetrating the Shock Front. The grains spiral inwards and penetrate the shock front smoothly as they uncouple from the gas shock. Grains are slowly decelerated by drag into a steady-state circular orbit; by then they have dissipated into heat half of their potential energy (GM/2r at radius $r$ ). The disk is optically thin near the shock front, so the grains may radiate away any rise in temperature (Levy 1988).

5.2.4. Coronal Flares. By analogy with the solar flares, a possible source of transient heating could exist in a hot corona outside of the disk. It is not clear whether it could be the transient source of heat needed to melt chondrules.

\subsection{THERMAL HISTORY OF THE SOLAR NEBULA}

Better and better numerical approximations of the protosolar accretion disk have been developed by Lin and Papaloizou (1985), Cameron (1985), Morfill et al. (1985), Wood and Morfill (1988), and Morfill (1988). Most authors rather agree on the general features, but there are yet slight differences depending on the basic assumptions. Models now try to take into account the variations in the optical depths in the nebula, introduced by the condensation of solids and the coagulation of grains. For instance, the feedback on opacity introduced by the evaporation of the grains stabilizes the temperature; this induces a temperature plateau near $1500 \mathrm{~K}$ for the silicates (from 0.1 to $0.5 \mathrm{AU}$ or more), and another one near 
$160 \mathrm{~K}$ for water ice (from 4 to $8 \mathrm{AU}$ or more) (Morfill 1988). Such a feedback keeps the disk optically thick even with a large doubt about the grain sizes due to their uncertain coagulation properties.

Two major parameters remain uncertain. The collapse rate of the molecular cloud fragment is known by order of magnitude only (typically $10^{-5 \pm 1}$ solar masses per year). Many authors compute only the steady-state disk, which corresponds to the maximum temperature and to a constant rate of mass flow from the collapsing cloud to the protostar through the disk. The viscous parameter is also uncertain (and hence the dissipation time of the disk as well), because the origin of the viscous friction in the disk has not been clarified. The friction probably comes from the turbulence in the nebular gas, induced by the vertical thermal gradients in the disk; it could, however, also be induced by a gravitational torque or a magnetic torque.

Fortunately, the dependence on temperature of these two parameters is rather well understood and is weak, and the temperature gradients do not change; outside the zones of the plateaus of condensation/vaporization, the mid-plane temperature typically varies with $\mathrm{r}^{-0.90}$, whereas the external (photospheric) temperature varies with $r^{-0.75}$. The uncertain parameters can be combined in a single variable, which must be adjusted empirically. The adjustment is usually done by using the condensation temperatures of the planets found by Lewis (1974). An example of this adjustment is given in Figure 5, from Morfill (1988). The crosses representing the positions of the planets are not error bars: they represent (horizontally) the range of distances of the zone that contributed to the planet's mass and (vertically) the corresponding range of temperatures. The success of the adjustment of the solid line to the planets' formation temperatures partially comes from the smooth gradient of about $\mathrm{r}^{-1}$ derived from Lewis' (1974) simple conceptual model, based on the condensation of solids from a cooling gas of solar composition, at thermochemical equilibrium. The density of solids diminishes roughly with the increasing volatility of the corresponding gas phase, and the global density of each planet is used to determine the temperature at which the condensation has stopped.

However, the condensation temperature also depends on the pressure of the gas phase; therefore, the proper use of the Lewis method requires the knowledge of the adiabat (temperature versus pressure). In Figure 6, the adiabat adopted in Cameron and Pine's (1973) model sets the positions of the planets (Lewis 1972). Lewis' original model used a cooling sequence starting at high temperature from a totally vaporized nebula, but early models of a dusty accretion disk have shown that this is not what happened. For illustrative purpose only, Figure 7 (from Cameron 1978) shows a possible temperature evolution in the zones corresponding to each of the planets: the temperature goes up first, then down after a maximum that varies with the radial distance.

Fortunately, a chemical equilibrium is a reversible situation; therefore the equilibrium condensation model remains valid for an "equilibrium vaporization" of dust. The major difficulty comes from the fact that the interstellar grains are likely to be mostly out of equilibrium to begin with, and chemical kinetics plays 


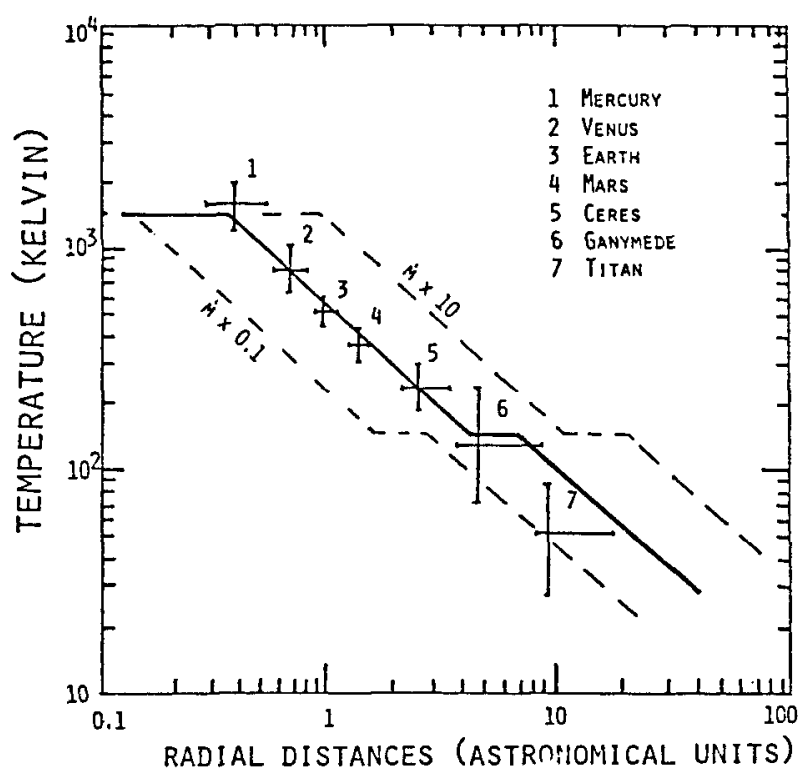

Figure 5. Adjustment of the mid-plane temperatures of a turbulent viscous disk model (Morfill 1988) to the Lewis (1974) aggregation temperatures of the planets. The crosses representing the different planetary bodies are not error bars: they describe the width of the accretion zones and the corresponding temperature ranges for the aggregation of each planet. The solid line is the adjusted model; the temperature gradient is in $\mathrm{R}^{-0.9}$, except for the two temperature plateaus that represent the condensation of silicates near $1500 \mathrm{~K}$ and of water ice near $150 \mathrm{~K}$. The two dotted lines correspond to accretion rates ten times larger and ten times smaller, respectively, than the nominal rate $\mathrm{M}$, assuming a constant viscosity parameter.

then an important role. In this respect, there is also (Morfill et al. 1985) the possibility of transporting dust radially by turbulent eddies, with alternate evaporation and condensation cycles.

\subsection{A HOTTER EARLY NEBULA}

In spite of the obvious success of Lewis' model in providing a realistic gradient for the formation temperatures of the planets, only their densities do not provide enough constraints to solve other cosmochemical problems.

For instance, the fractionation of iron from silicates is required by the different classes of chondrites as well as by the composition of the Earth (see Figure 4). The reason why such a fractionation requires a temperature on the 


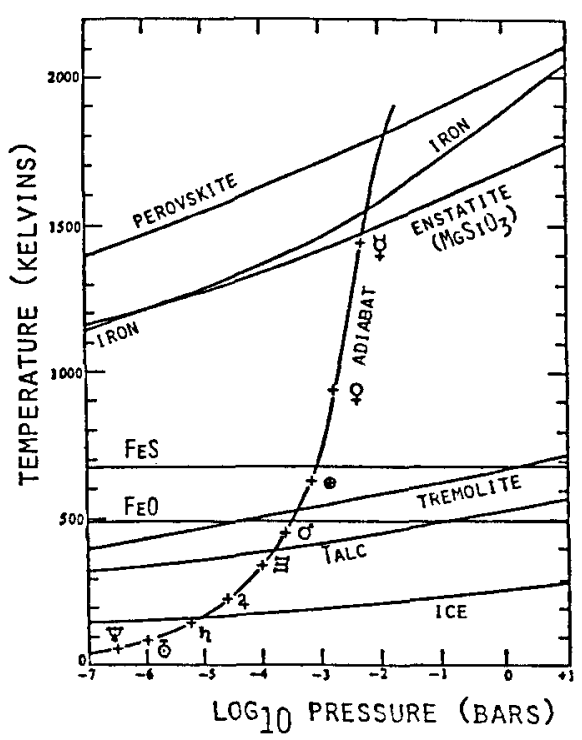

Figure 6. Chemical condensation of minerals at thermal chemical equilibrium in a gas of solar composition. $\mathrm{CaTiO}_{3}$ is used as an example of a refractory mineral. At higher pressures, iron condenses at a higher temperature than enstatite, the representative silicate with magnesium. This is a mechanism for the iron-silicate fractionation mentioned in the text. Fe is wholly oxidized in $\mathrm{FeO}$ for temperatures lower than $500 \mathrm{~K}$. The position of the adiabat explains the densities of all the planets. From Lewis (1972b).

order of $1500 \mathrm{~K}$ can be seen in Figure 6; the fractionation must take place in the zone lying between the condensation curves of $\mathrm{Fe}$ and $\mathrm{MgSiO}_{3}$, which diverge at high pressures and temperatures. However, see Larimer and Anders' (1970) suggestion.

Other telltales of high temperatures are the existence of chondrules and of calcium-aluminum inclusions in the matrix of many chondrites. Calcium-aluminum inclusions correspond roughly to the first $5 \%$ of solids to condense out of a gas of solar composition. Alternately, they can be the last $5 \%$ of solid residues after volatilization. Both processes imply temperatures of at least $1700 \mathrm{~K}$ (Wood and Morfill 1988). Chondrules are silicate spherules that have been melted at temperatures in the range of 1700 to $1900 \mathrm{~K}$ (Grossman et al. 1988). Both chondrules and refractory inclusions have been eventually mixed with particles processed at a lower temperature--including organic matter in carbonaceous chondrites--and finally compacted together. 


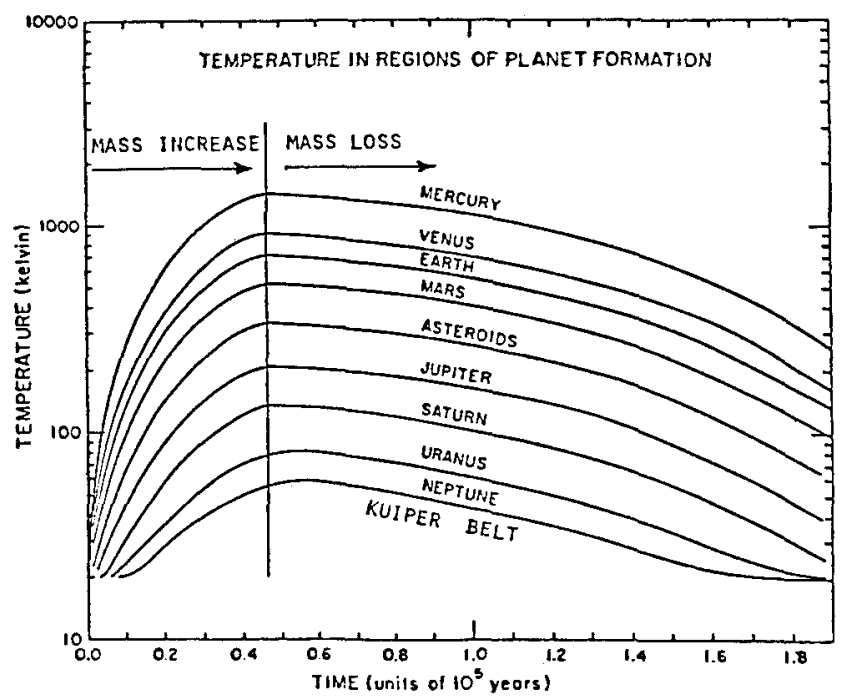

Figure 7. Evolution of the temperature in the viscous accretion disk, in the different zones of temperature formation. The disk temperature and the mass grow as long as the infall is larger than the mass feeding rate of the protostar; they diminish as soon as the infall subsides to smaller values. When the infall stops, gas turbulence stops in the disk, and dust grains or aggregates sediment to the mid-plane, where they will agglomerate into planetesimals. From Cameron (1978).

These facts imply that Lewis' condensation temperatures do not coincide with the maximum temperatures suggested by Figure 7, and they do not have to, provided the cooling of the accretion disk was slow enough to keep a thermochemical equilibrium until solids separated from the gas (by dust sedimentation to the mid-plane). This implies that dust was kept in suspension by turbulent eddies in the gas during the whole cooling phase. Hence the infall of nebular matter went on at a slower pace for a long time to keep turbulence going. Cameron (1985) has described four viscous disk models (which he calls A, $\mathrm{B}, \mathrm{C}$, and D) corresponding to steady-state cases with four different mass inflow rates. His model A produces mid-plane temperatures beyond $1600 \mathrm{~K}$ up to $3 \mathrm{AU}$ (needed for the fractionation iron/silicates in the chondrites of the asteroid belt). Depending on the value of the viscosity constant adopted, the influx rate $\mathrm{M}$ of such a disk is between $4 \times 10^{-5}$ and $5 \times 10^{-5} \mathrm{M}_{\odot} \mathrm{yr}^{-1}$. Of course, Lewis' condensation sequence does not fit in with this steady state, but if the nebular 
infall does not stop instantly, the disk will remain stirred by turbulence while adjusting to a quasi-steady state with a lower temperature everywhere.

Lewis' temperatures are slowly reached in the mid-plane for a case between Cameron's models $C$ and $D$, when the influx rate is between $7 \times 10^{-7}$ and $9 \times 10^{-7} \mathrm{M}_{\odot} \mathrm{yr}^{-1}$. There is no conceptual difficulty imagining that the influx rate went down to this low value before its complete stop. Iron/silicate fractionation, as well as refractory inclusions, would be the vestigial remnants of the phase A hot disk, whereas Lewis temperatures would be the cooler phase C-D adiabat in existence when the infall stopped, making the turbulence subside and the dust sediment to the mid-plane. The only problem that this scenario would not solve is the fast quenching time of the chondrules (thousands of $\mathrm{K}$ per hour, Grossman 1988); they imply fast energetic events, such as the possible discharges in the disk corona (see Section 5.2.4).

The previous scenario implies that the interstellar grains had divergent heating histories. The early ones lost their mantles up to $30 \mathrm{AU}$ and even a fraction of their iron up to $3 \mathrm{AU}$. The latecomers kept their snows beyond $4 \mathrm{AU}$ and their silicates beyond $0.4 \mathrm{AU}$. The early ones had more time to be transported to different radial distances by turbulence before their sedimentation. However, their temperatures never were large enough to completely erase their isotopic anomalies, which are now found in the chondrites (Kerridge and Chang 1988, Clayton et al. 1988). Only the refractory organics survived at $3 \mathrm{AU}$; the volatile organics were fractionated between 3 and $10 \mathrm{AU}$.

\subsection{CARBON CHEMISTRY IN THE ACCRETION DISK}

The previous discussion was useful to establish the framework of what is possible about the temperature evolution in the solar accretion disk and the thermal processing of silicates in the asteroid belt. It is reasonable to believe (Wetherill and Chapman 1988) that the asteroid belt is the source of most chondrites. Morrison (1977) has established that the $\mathrm{C}$ asteroids begin to outnumber the $\mathrm{S}$ asteroids at distances beyond 2.6 AU. The $\mathrm{C}$ asteroids are associated with meteorites rich in opaque minerals with low albedos, that is, the carbonaceous chondrites. See, however, Wetherill and Chapman for a discussion of the controversy about the identification of the S asteroids.

If we make the plausible assumption that the 2.6-AU distance separates the condensation temperatures of carbonaceous chondrites from those of the other chondrites, this criterion represents a sensitive cosmothermometer because of the volatility of many carbon compounds and because of their behavior at thermochemical equilibrium in a gas of solar composition. Figure 8 represents this equilibrium. The three quasi-vertical curves represent three adiabats through the mid-plane of the accretion disk. Models C and D come from Cameron's (1985) data. Model CD is an interpolation of models C and D that fits in better with Lewis (1972) data derived from the planets densities (see Figure 6). The other solid lines separate the domains in which $\mathrm{CH}_{4}, \mathrm{CO}, \mathrm{CO}_{2}$ and $\mathrm{C}_{\mathrm{s}}$ (graphite) are the most abundant carbon compounds. 


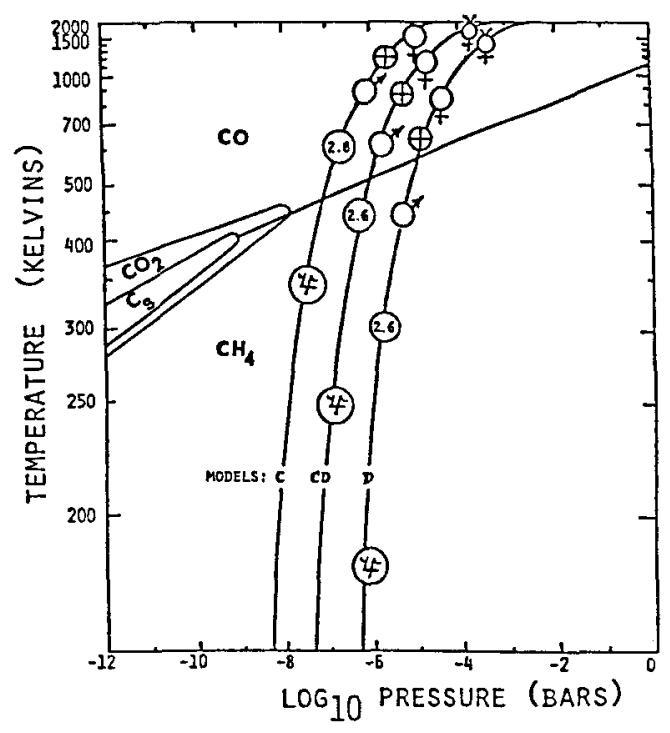

Figure 8. The thermochemical equilibrium diagram for carbon compounds in a gas of solar composition. The quasi-vertical curves represent the adiabats of Cameron's (1985) models C and D. Model C-D is an interpolation of the two previous models that brings the zone at $2.6 \mathrm{AU}$ at the temperature where FischerTropsch-type reactions are catalyzed by grains of silicate in the accretion disk. Models C, C-D, and D may represent a cooling sequence in the disk. The separation of carbonaceous chondrites from other chondrites at 2.6 AU may signify that dust sedimentation (and hence the end of the infall) took place at a time when adiabat $\mathrm{C}$-D was representative of the conditions in the disk. The other lines separate the zones where $\mathrm{CO}, \mathrm{CH}_{4}, \mathrm{CO}_{2}$, or $\mathrm{C}_{\mathrm{s}}$ (solid carbon) are each the major constituent. If adiabat $C-D$ is applicable to the Earth's conditions, then all carbon was in $\mathrm{CO}$ in the Earth's zone, and the origin of carbon on Earth must be exogenous.

Anders (1986) has discussed in great detail the possible origin of the rich organic chemistry present in carbonaceous chondrites. He has repeatedly concluded that the hydrogenation of $\mathrm{CO}$ in the presence of a solid catalyst (iron oxide $\mathrm{Fe}_{3} \mathrm{O}_{4}$ or hydrated silicates) is the only known formation process that strongly favors straight over branched hydrocarbon chains (see also his review in 1971), as observed in carbonaceous chondrites. This reaction had been proposed earlier by Studier, Hayatsu and Anders (1968) to explain the carbon chemistry of the carbonaceous chondrites. It is the famous reaction discovered by Fischer and Tropsch and used in Germany during the second World War to make gasoline 
from coke-oven gas. Many similar reactions (some also involving nitrogen) have been dubbed Fischer-Tropsch-type or FTT by Anders and co-workers.

Laboratory experiments have shown that all organic compounds reliably identified in carbonaceous chondrites can be produced from $\mathrm{CO}, \mathrm{H}_{2}$ and $\mathrm{NH}_{3}$ on a $\mathrm{Fe}_{2} \mathrm{O}_{3}$ or clay catalyst (Hayatsu and Anders 1981). All we have to do to produce these organic compounds in the accretion disk is follow the adiabat until it reaches 400 to $430 \mathrm{~K}$; the proper catalyst is already there in the form of fine dust, and the organic matter will condense on the dust. In Figure 8, the only adiabat satisfying the requirements at $2.6 \mathrm{AU}$ is model $\mathrm{CD}$. The FTT reactions work here because carbon activity goes through a maximum where the adiabat crosses the line separating the two domains where $\mathrm{CO}$ and $\mathrm{CH}_{4}$, respectively, prevail.

The early heating phase of the accretion disk, mentioned in Section 5.3, implies that the previous scenario is the only possible one, because any trace of the organic chemistry of the interstellar grain mantles has been previously destroyed by heat (with the exception of the refractory, cross-linked, semicrystallized, ill-defined carbon compounds, such as the PAH particles, that could survive). Specific stellar origins have indeed been inferred from isotopic anomalies for some of these refractory grains (Anders 1986). The 2.6-AU distance separating carbonaceous chondrites from other chondrites probably provides the best criterion to select the proper adiabat in the condensation sequence proposed by Lewis.

\subsection{THE EXOGENOUS ORIGIN OF CARBON ON THE TERRESTRIAL PLANETS}

The origin of carbon on the terrestrial planets is not trivial, because of the mounting evidence that, at the time when the largest planetary bodies were not much larger than grains of dust, there was a high-temperature period in the zones of the future terrestrial planets. Without even alluding to the possible temperature spike that may have reached some $1800 \mathrm{~K}$ near $3 \mathrm{AU}$, the cooler steady state reached just before the end of the infall period is described by adiabat C-D. It shows that, shortly preceding the dust sedimentation in the midplane of the accretion disk, in the zone of Mars the temperature was close to $620 \mathrm{~K}$, that of the Earth close to $860 \mathrm{~K}$, that of Venus near $1200 \mathrm{~K}$ and Mercury near $1800 \mathrm{~K}$. This is close enough to the accretion temperature of the planets deduced by Lewis to confirm his general view, although adiabat $C D$ is probably based on a more appropriate model of the disk.

These rather high temperatures imply that, just before the accretion of the planets, all dust was outgassed and most carbon was stored in the gas phase in the zone of the terrestrial planets. The existence of reduced iron in the fine dust grains of the disk, in contact with a large amount of $\mathrm{H}_{2}$ at a temperature between 800 and $900 \mathrm{~K}$, explains the origin of the Earth's nucleus. Reduced iron can eventually sink to the center of the Earth, whereas iron oxides or silicates could neither be easily reduced when imprisoned in the Earth's mantle, nor sink in an 
oxidized form. The dust composition in the Earth's zone, when it settled down to the mid-plane, is revealed by the Earth's place in Figure 4 (about $70 \%$ reduced iron and $30 \%$ silicates of iron and magnesium), at least for its major elements.

Are the kinetics of the chemical reactions sufficiently rapid for the disk to reach chemical equilibrium? The characteristic times available after the disk becomes quiescent and the dust sediments in the mid-plane are given by Weidenschilling's (1988) analysis. He remarks that the gravitational instabilities traditionally involved to make planetesimals will not work, because the differential motion between dust and gas will keep too much turbulence for the density to become critical. He predicts growth by coagulation of grain clusters reaching up to meter-sized bodies in a few thousand years, kilometer-sized bodies in $10^{4}$ years, and asteroid-sized bodies in $10^{5}$ years.

The chemical kinetics in a gas of solar composition have been very carefully and thoroughly discussed by Lewis et al. (1979) and Lewis and Prinn (1980). The largest time constants that turn out to be significant are on the order of one century near $1000 \mathrm{~K}$; therefore thermochemical equilibrium will be reached before solids are completely separated from the gas phase. This means that the dust has been completely dehydrated, outgassed and reduced (except a fraction of silicate grains) before its incorporation into planetesimals and their later integration into planetary bodies.

Lewis et al. (1979) have, in particular, considered the carbon problem, and they have been puzzled by the retention of carbon in the terrestrial planets. Searching for a mechanism of carbon retention, they deduce that the only way to imprison carbon in the solid phase is to put it in solid solution in metallic iron grains; in spite of their efforts, they reach an amount two or three times smaller than the observed amount on the Earth or Venus, and they do not address the question on how to bring this carbon to the surface of the Earth.

However, in order to reach an amount of carbon as large as possible, their choice for the adiabat has put the Earth's zone near the peak of graphite activity. For any adiabat, graphite activity goes through a maximum in the vicinity of the line separating the domains of $\mathrm{CH}_{4}$ and $\mathrm{CO}$ in Figure 8, as mentioned previously. Putting the Earth there removes the 2.6-AU zone from the same place, whatever the model. Therefore Lewis et al.'s (1979) quite reasonable efforts to explain the presence of carbon on the Earth have removed the FTT reaction zone from the asteroid belt to bring it to the Earth!

If adiabat $\mathrm{CD}$ is used in order to get the FTT reactions at the proper place, then (using Lewis et al.'s own data) the amount of carbon available for direct condensation on the Earth and Venus becomes several hundred times smaller than the observed amounts on these planets. Hence the interpretation of the organic compounds in carbonaceous chondrites as the result of FischerTropsch-type reactions strongly implies that the bulk of the observed carbon on the terrestrial planets has an exogenous origin. Such an origin can be explained in a straightforward manner by an inevitable orbital evolution taking place during the final phases of planetary accretion. 


\subsection{ORBITAL DIFFUSION AS THE ORIGIN OF EXOGENOUS MATERIAL}

After planetesimal accretion, larger planetary embryos will grow from numberless low-velocity collisions, since all bodies are in quasi-circular orbits of very low inclination (Wetherill 1980), and at this stage a few bodies in the size range from 200 to $500 \mathrm{~km}$ are already being produced in some 20,000 years (Greenberg et al. 1978). As soon as there are bodies whose gravitational attraction cannot be neglected any more, these larger bodies sweep up smaller objects more efficiently because they attract them from afar. This "gravitational focusing" has two effects: first, there is a runaway growth of the largest bodies, and second, the close encounters that do not end in collisions are going to enlarge the inclinations and the eccentricities of the smaller objects' orbits (Safronov 1969).

At steady state between velocity damping by collisions and velocity increase by grazing misses, Safronov (1969) finds that the mean relative velocities in the swarm of smaller bodies grow in proportion to the escape velocity of the largest body. This important result contains already the inescapable conclusion that more and more volatile materials, including carbon compounds, will be brought from farther and farther away. The reason is that the relative velocity growth is produced by orbital changes that enlarge the zone swept by the minor bodies. Since this occurs everywhere, the Earth embryo will eventually be hit by bodies coming from larger and larger distances, including from the asteroid belt and beyond, because of the growth of Jupiter's embryo.

This is not the place to review the difficult question of Jupiter's formation. However, Wetherill and Chapman (1988) show that a runaway growth of a Jupiter core of several Earth masses is possible in half a million years. This seems to happen just in time for a massive Jupiter to stop the formation of a planet in the asteroid belt. Since this is the only mechanism that has been proposed for this purpose, the absence of a planet at $2.8 \mathrm{AU}$ is a reasonable argument that a massive Jupiter existed after only a few million years.

During the final stages of its accretion, a very large number of the planetesimals present in the asteroid belt as well as in Jupiter's own accretion zone, were forced into more and more elongated orbits and finally penetrated the accretion zones of the terrestrial planets, at a time when their accretion was nearing the end.

It is possible to estimate the mass accreted on the terrestrial planets by this mechanism of orbital diffusion. Using the model I proposed previously (Delsemme 1981, 1984), it is easy to compute the contribution of each zone, with the exception of the asteroid zone, where the mass of the missing planet is not known. In order to demonstrate that the chondrite contribution is not so large, I have chosen the unrealistic assumption of $10 \mathrm{M}_{\mathrm{o}}\left(\mathrm{M}_{\mathrm{o}}\right.$ is the mass of the Earth) for the material that was available in the asteroid zone. In spite of this, the chondrite contribution remains much smaller than that of the planetesimals of further-away Jupiter. 
Table 13. The Exogenous Origin of Water and Organic Matter on Earth ${ }^{\mathrm{a}}$

\begin{tabular}{|c|c|c|c|c|c|}
\hline ORIGIN OF & MASS SHED TO & THICKNESS & OF UNIFC & M LAYER O & EARTH \\
\hline PLANETESIMALS & EARTH'S ZONE & SILICATES & WATER & ORGANICS & GASES \\
\hline $\begin{array}{l}\text { Chondrites From } \\
\text { Asteroids' Zone }\end{array}$ & $1.30 \mathrm{M}_{0}$ & $1 \mathrm{~km}$ & $10 \mathrm{~m}$ & $5 \mathrm{~m}$ & --- \\
\hline $\begin{array}{l}\text { Comets From } \\
\text { Jupiter's Zone }\end{array}$ & $3.7 \mathrm{M}_{0}$ & $2 \mathrm{~km}$ & $4 \mathrm{~km}$ & $1 \mathrm{~km}$ & 200 bars \\
\hline $\begin{array}{l}\text { Comets From } \\
\text { Saturn's Zone }\end{array}$ & 0.8 & $0.5 \mathrm{~km}$ & $1 \mathrm{~km}$ & $200 \mathrm{~m}$ & 4 bars \\
\hline Totals: & $5.8 \mathrm{M}_{0}$ & $3.5 \mathrm{~km}$ & $5 \mathrm{~km}$ & $1.2 \mathrm{~km}$ & 240 bars \\
\hline
\end{tabular}

a Notes: $\mathrm{M}_{0}$ represents the mass of the Earth. The missing mass in the asteroids' zone is assumed to be $10 \mathrm{M}_{0}$. The chondrites are assumed to be $10 \%$ carbonaceous and $90 \%$ ordinary. The thickness of the layer was deduced from the mass shed to the zone times the collision probability with Earth. The masses scattered by the giant planets are from Safronov (1972). Fernandez and Ip $(1981,1983)$ find an order of magnitude more than Safronov. The insoluble organics are counted in the stony fraction with the silicates. The atmospheric gases come from Table 6 ; they are those that would still be in the gas phase at 240 bars. The present oceans would make a uniform layer of $2.6 \mathrm{~km}$.

Table 13 shows the result of this orbital diffusion mechanism for the specific case of the Earth. The fact that the major contribution comes from Jupiter's zone does not come as a surprise. The last columns show the thickness of the veneer and the pressure of the released gases (mostly $\mathrm{N}_{2}+\mathrm{CO}+\mathrm{CO}_{2}$; see Table 6). Everything is made under the assumption that Comet Halley is representative of the planetesimals of the zones of Jupiter and beyond. The amount of water brought down to Earth corresponds to twice the water extant in the oceans now.

Recent evaluations rather confirm my Table 13, although they seem to go somewhat beyond my results. For instance, Matsui and Abe (1986) find that comets have brought down to Earth four times as much water as the mass of our oceans. Ip and Fernandez $(1981,1983)$ have revised Safronov's evaluations and found that the mass perturbed towards the orbits of the terrestrial planets is more than an order of magnitude larger than Safronov's figures. Therefore it is not surprising that in 1988, they find that ten times the present mass of our oceans has been brought down to Earth. Chyba (1987) uses the visible craters of the Moon to estimate the latest bombardment. He finds that the total mass of our oceans is explained if only $10 \%$ of the extant craters are due to comets. 
These higher estimates are not in contradiction with the present amount of oceanic water, because there is a serious possibility that a large fraction of this water, and even a larger fraction of the atmosphere, has been eroded by one or several giant impacts, implying lunar-size or even Mars-size colliding objects during the final phases of the accretion of the terrestrial planets. Late giant impacts of this type are indeed predicted by the agglomeration theory, and it is possible that one of these last collisions was the cause of the Moon's formation. The atmosphere of Mars would also have been much more depleted by this type of collision because of the smaller gravity of this planet (Cameron 1988).

It is interesting to note that some cosmochemical models of the terrestrial planets have converged to the same conclusion of an inhomogeneous accretion. This is the case for the "chondrite model" (Larimer and Anders 1970) that uses a mixture of a limited number of individual components recognized in the chondrites, to build the individual planets. The recent version of this model (Anders and Owen 1977) assumes that volatile elements were added at least on the Earth and Mars as an accretion veneer of carbonaceous chondrites. The diffusion of the planetesimals' orbits now provides the missing data and also the approximate proportions of chondrites and comets that were arbitrary in the "chondrite model."

\subsection{THE ORIGIN OF COMETS}

As discussed in Section 5.3, the variable fractionation of iron in silicates present in the carbonaceous chondrites as well as in the Earth makes it essential that the infall rate of the interstellar cloud fragment diminished during the existence of the accretion disk. After all, this is not so surprising, since only a singular isothermal sphere collapses at a constant mass rate $M$ (Shu et al. 1987). It seems more reasonable to believe that, if the central core collapses at a rate that is about constant, its edge, which fades away in the surrounding cloud, is going to follow suit at a steadily diminishing rate.

This scenario implies that the disk was much more massive at the beginning, and hence extended very far away, probably at more than $500 \mathrm{AU}$. This is supported by the view that the orbital symmetry of short-period comets cannot be produced by orbital diffusion from a spherical source like the Oort cloud (Duncan et al. 1988). Instead, these comets must come from a source that already has a flattened distribution. This "Kuiper belt" was never detected gravitationally and remained hypothetical until Duncan et al. demonstrated that short-period comets must come from it.

Further evidence for the size of the Kuiper belt comes from the fact that many dust disks around single stars like Beta Pictoris extend $500 \mathrm{AU}$ or more in radius. If the early disk was massive enough to reach a radius of $500 \mathrm{AU}$ or more, objects beyond $500 \mathrm{AU}$ have periods larger than 10,000 years, and a large loss of mass in the disk occurs in less than one of their periods. This is enough to put a large mass of these objects on highly elliptical trajectories, according to the theory of the Oort cloud formation proposed by Cameron (1978). This theory 
cannot work with less massive and smaller disks. The alternate source for the Oort cloud, proposed by Safronov (1972), namely the diffusion of the planetesimals' orbits from the zones of the giant planets, must also have been effective. After all, it is another consequence of the same orbital diffusion that brought a veneer of a volatile matter on the terrestrial planets.

However, the total mass of the Oort cloud found by Safronov (mostly from the zones of Uranus and Neptune) is only 2.5 Earth masses. Ip and Fernandez $(1981,1983)$ have revised Safronov's assessment upwards by at least an order of magnitude. Even so, this cloud could have been considerably depleted by only two or three encounters between the Solar System and giant molecular clouds (Clube and Napier 1984). The advantage of Cameron's proposal is that it provides a robust inner cloud of a much larger mass, in the form of a Kuiper belt that will easily survive for the duration of the Solar System. The problem is compounded by the existence of the vertical galactic tide. Its detection by me (1987) shows that it was stronger than expected (see my review, 1989). The larger invisible mass in the galactic disk that is implied makes a secular diffusion of the inner Oort cloud more likely, because of numerous brown dwarfs passing through.

Safronov comets could have survived until now because many could have stayed in the inner cloud, but they are likely to be vastly outnumbered by the Kuiper-belt comets. In principle, these comet types could be distinguished chemically as well as physically. The Safronov comets could have a different temperature history as well as a different size distribution. Formed when adiabat C-D was reached, most of them (from the Uranus-Neptune zone) accreted at 50 to $70 \mathrm{~K}$. The rarer objects from the Saturn-Jupiter zone could have accreted between 100 and $150 \mathrm{~K}$. Some were ejected when they were already larger bodies, due to the accumulation process of the early planetesimals. In contrast, the Kuiper-belt comets must have formed much further away. Even if grain sedimentation was early and if Cameron's warmer adiabat A is used, most of them would still be formed at temperatures lower than $40 \mathrm{~K}$ (see Section 5.2.2).

To summarize, the chemical evidence for a hotter phase early in the solar nebula implies the existence of a larger and more massive early disk that shed out a massive Kuiper belt of comets, which was later enlarged in diameter by shedding the inside mass (bipolar flow, $\mathrm{T}$ Tauri wind, etc.). The impulsive orbital changes mentioned by Cameron (1978) have also pushed the aphelia radially away in the belt, whenever the shedding inside an orbit was much shorter than its period. The flat orbital diffusion of the short-period comet system has confirmed the existence of the Kuiper belt, and its large size is supported by the size of the dusty circumstellar disks that have been detected. Finally, the detection of strong vertical galactic tides implies the existence of numerous dark objects that compete with ordinary stars to perturb the outer fringe of the Kuiper belt and constantly replenish the Oort cloud.

The consistency of this picture is such that it makes other hypotheses on the origin of comets less attractive. In particular, none of the other hypotheses reviewed recently by Weissman (1985) and Hill (1986) is supported by a sequence of so many consistent observational facts. 


\section{Conclusion}

\subsection{DISCUSSION}

6.1.1. Large-Scale Homogeneity. In the bulk analysis of Comet Halley, the seventeen elements that have been measured are all extremely close to their relative proportions in the Sun, with the exception of hydrogen, which is depleted by a factor of 500 . In particular, the most volatile elements $\mathrm{C}, \mathrm{N}, \mathrm{O}$, and $\mathrm{S}$, which are very depleted even in the most pristine meteorites, the carbonaceous chondrites, are extremely close to solar proportions in Comet Halley. These elements are, of course, the source of the rich organic chemistry displayed in comets.

6.1.2. Microscopic Diversity. This bulk homogeneity is so close to the Sun's abundances that it must stem from a common origin. This implies that the primeval composition of the common source has been much better preserved in comets than in carbonaceous chondrites. It comes, then, as a major surprise that this primeval composition reveals an extremely large chemical diversity at the level of microscopic grains of dust.

\subsubsection{Puzzle of the Fe/Si Scatter. Another surprise comes from the fact that the} bulk abundance ratio of two major elements in Comet Halley is not strictly solar. The $\mathrm{Fe} / \mathrm{Si}$ ratio is $0.28 \pm 30 \%$ in Comet Halley, compared with $1.32 \pm 20 \%$ in the Sun: they are apart by much more than the nominal error bars. This could be easily dismissed as a poorly understood fluke in the experiments, if it were not associated with two long-standing problems. The first one is the long debate about the abundance of iron in the Sun, which has now been properly solved (Grevesse 1984, Anders and Grevesse 1989). The second one is the origin of the well-established existence of the $\mathrm{Fe} / \mathrm{Si}$ ratio scatter in the different types of chondrites (Figure 4), which seems to require a variable iron/silicate fractionation at high temperatures (Section 5.4).

In Comet Halley, Jessberger et al. (1988) consider that it is probably safer to attribute the deviation of the Fe/Si ratio to the uncertainty of the ion yields used to interpret the mass spectrometry data, but they recognize that by doing so, they may have missed an important finding! A statistical analysis is premature because first, all results have not yet been published, and second, the 79 grains have a multimodal distribution: their abundances scatter into four distinct groups mentioned in Section 3.2, namely groups A, B, C and D. The anomalous $\mathrm{Fe} / \mathrm{Si}$ ratio is mainly introduced by the existence of Group $\mathrm{C}$, where the large depletion of $\mathrm{Fe} / \mathrm{Si}$ could not come from instrumental uncertainties only. The grains of this group seem to require a high-temperature fractionation (typically 1500 to $1600 \mathrm{~K}$; see Figure 6) before their sedimentation with the other groups of different thermal histories. This explanation seems to make more sense because it is 
basically the same as the one used to explain the heterogeneity of the matrix of the chondrites as well as their Fe/Si depletion.

There do not seem to be many other possible explanations. The abundance of iron in the Sun could still be too high, and the measure of the $\mathrm{Fe} / \mathrm{Si}$ ratio in Comet Halley could be a fluke or an artifact of the fast flyby, but the $\mathrm{Fe} / \mathrm{Si}$ scatter in the different types of chondrites is real because it has been abundantly substantiated.

\subsubsection{A Hot or a Cold Iron Fractionation? If the $\mathrm{Fe} / \mathrm{Si}$ scatter does not come} from a high-temperature fractionation, either in chondrites or in comets, a cold process must be invoked in the period when iron grains were still separated from silicate grains, that is before their accumulation in planetesimals. The process should achieve a variable separation of the iron grains at different places in the accretion disk; it would therefore probably involve the magnetic properties of the iron grains, as opposed to the dielectric properties of silicates (Larimer and Anders 1970). The agent could be the magnetic field induced by ionization of the rotating disk corona, the same one that assumedly focuses the bipolar flow of the solar wind.

But then why are comets the most depleted in iron, since they form the furthest radially away? And where has all the iron dust gone? Not in the planets' cores, as substantiated by the Earth's position on the Urey-Craig diagram of Figure 4. Has it gone into the solar photosphere, where an iron enrichment could explain the present high value of the solar Fe/Si ratio? Conjectures of this type are probably quite premature, since the answers may not be settled before other successful cometary missions.

6.1.5. Interstellar Origin of Grains. The heterogeneity of Comet Halley's grains, in particular, the dispersion of their elemental abundances and their clustering into four families (Section 3.2), is in agreement with their possible interstellar origin. The interpretation of the optical properties of the interstellar grains requires a rather heterogeneous mixture of different particles that is also in agreement with their assumed origin in the outflows of oxygen-rich as well as carbon-rich stars, that is, in the variable environment of either oxidizing or reducing conditions. In particular, the ill-defined organic refractory polymer approximated by polyaromatic hydrocarbons also seems to be present in the insoluble organic material found in abundance in carbonaceous chondrites (Wdowiak et al. 1988), as well as in the refractory organic grains of Comet Halley. The refractory nature of such a polymer explains why it has survived in chondrites after a 400 to $500 \mathrm{~K}$ heating in the solar nebula (Section 5.3) or even after much higher temperatures in an early phase (Section 5.4). Such a thermal evolution also explains the possibility of the FTT reactions, needed to explain the prevalence of straight branch chains in the organic molecules found in carbonaceous chondrites.

6.1.6. The Prebiotic Molecules. These FTT reactions also seem to be required to explain the numerous amino-acids found in carbonaceous chondrites. In contrast, 
the absence of any significant thermal processing in comets may have quenched in their grains the unequilibrated results of the interstellar chemistry. This could mean that the glimpse of the organic chemistry of Comet Halley's grains is really the first glimpse of those large molecules still to be discovered in interstellar space. They may include more cyclic molecules (since $\mathrm{C}_{3} \mathrm{H}_{2}$ is still the only cyclic molecule discovered in interstellar space). In particular, the heterocyclics that include purine and pyrimidines tentatively identified in Comet Halley could come straight from interstellar space and also be preserved in chondrites, where they have indeed also been found.

\subsubsection{Formation of Comets. There is no satisfactory accretion model of comets} in the Kuiper belt, in the sense that their size distribution has not been predicted. The whole issue turns around the coagulation properties of interstellar grains, which are unknown; the growth of grain sizes is already possible during the infall of matter, but it is the sedimentation to the mid-plane of the disk that seems to be the decisive mechanism for grain accumulation. At the limit, comet agglomeration could have taken place even in interstellar space, but the essential feature is that the comets' constituents have never been heated at more than $30 \mathrm{~K}$, except if there are still Safronov comets whose accretion took place in the zones of the giant planets, in existence; they should be easily recognized because of their formation at a much higher temperature. If our previous interpretation is correct, the temperature of formation for the group $\mathrm{C}$ grains would imply that Comet Halley is a Safronov comet.

\subsection{SUMMARY}

The organic compounds observed in interstellar space, in carbonaceous chondrites and in comets seem to be connected by a cosmic evolution that is beginning to be unravelled. The common origin of comets and chondrites stems from the condensation of a frost of interstellar molecules on the colder solid grains present in dense molecular clouds. These dense clouds are those whose fragments can collapse gravitationally. Frosty grains followed suit in the collapse that formed an accretion disk surrounding and feeding the protosun. They went through a variable thermal evolution depending on their radial distance in the disk. Carbon compounds were vaporized up to 2 or $3 \mathrm{AU}$, and water up to $5 \mathrm{AU}$.

This thermal evolution must still be clarified, and it will be when the variable fractionation of iron from silicates is understood. There is, however, some evidence that FTT reactions near 400 to $430 \mathrm{~K}$ produced most of the complex chemistry found in carbonaceous chondrites, whereas comets were formed from a colder grain agglomeration and hence much further away, probably 50 to $500 \mathrm{AU}$ in the Kuiper Belt. This means that they have kept the large diversity of individual grains almost in their pristine condition of interstellar space. If not a fluke in the experiment, the depletion of iron in the grains of Comet Halley remains one of the major puzzles that might not be solved before new cometary missions. Mercury, the closest object to the Sun, has the most iron. 
Comets, the furthest away from the Sun, have the least iron; the Earth and the chondrites have intermediate values. Here is another of the peculiarities of the Solar System that must mean something, even if we do not understand the message clearly.

Another important result of the thermal evolution of the accretion disk and the subsequent agglomeration of planetary bodies is the necessity of an exogenous origin of carbon and water on the Earth, explained by the inevitable diffusion of cometary orbits. By colliding with the Earth in the final phases of planetary accumulation, chondrites and comets, particularly the latter, have brought a veneer of volatile molecules explaining the origin of the biosphere.

\section{ACKNOWLEDGMENTS}

I thank two referees and the editors for constructive comments, and Ed Anders for a fruitful exchange of letters. NASA's grant is gratefully acknowledged. 


\section{REFERENCES}

Adams, F.C., and Shu, F.H. (1985). Astrophys. J., 296, 655-669.

Adams, F.C., and Shu, F.H. (1986). Astrophys. J., 308, 836-853.

Anders, E. (1986). In Comet Nucleus Sample Return, O. Melita (ed.), Paris, ESA SP249, pp. 31-39.

Anders, E., and Grevesse, N. (1989). Geochim. Cosmochim. Acta, 53, 197-214.

Anders, E., and Owen, T. (1977). Science 198, 453-465.

Avery, L.W. (1980). In Interstellar Molecules, B. Andrew (ed.), D. Reidel Publishing Co., Dordrecht, p. 47.

Appenzeller, I., and Jordan, C. (eds.) (1987). Circumstellar Matter, IAU Sympos. 122, D. Reidel Publishing Co., Dordrecht.

Balsiger, H., Altwegg, K., Buhler, F., et al. (1986). Nature 321, 330-334.

Barbieri, C., Cremonese, G., and Fulle, M. (1987). In Abstracts, Diversity and Similarity of Comets, ESA, Paris, p. 131.

Baron, Y., deMuizon, M., Papouar, R., and Pegourie, B. (1987). Astron. Astrophys. $186,271-279$.

Benz, W., Slattery, W.L., and Cameron, A.G.W. (1987). Icarus 71, 30.

Black, H.J., and Willner, S.P. (1984). Astrophys. J., 279, 673-678.

Bobrovnikoff, N.T. (1931). Publ. Lick Observ. 17, 309.

Brownlee, D.E., Wheelock, M.M., Temple, S., Bradley, J.P., and Kissel, J. (1987). J. Lunar Planet. Sci. Conf. 18, 133-134.

Cameron, A.G.W. (1975). Icarus 24, 128-133.

Cameron, A.G.W. (1978). In The Origin of the Solar System, S.F. Dermott (ed.), Wiley and Sons, New York, pp. 49-74.

Cameron, A.G.W. (1983). Icarus 56, 195.

Cameron, A.G.W. (1985). In Protostars and Planets II, D.C. Black and M.S. Matthews (eds.), University of Arizona Press, Tucson, pp. 1073-1099.

Cameron, A.G.W. (1988). Ann. Rev. Astron. Astrophys. 26, 441-472.

Cameron, A.G.W., and Pine, M.R. (1973). Icarus 18, 377-406.

Campbell, D.B., Harmon, J.K., and Shapiro, I.I. (1989). Astrophys. J., 338, 10941105.

Cernicharo, J., Gottlieb, C.A., Guelin, M., Thaddeus, P., and Vrtilek, J.M. (1989). Astrophys. J. Lett., 341, L25-28.

Chyba, C.F. (1987). Nature 330, 632-635.

Clayton, D.D. (1980). Astrophys. J., 239, L37-L41.

Clayton, R.N., Mayeda, T.K., and Molini-Vesko, C.A. (1988). In Protostars and Planets II, D.C. Black and M.S. Matthews (eds.), University of Arizona Press, Tucson, pp. 755-771.

Clube, S.V.M., and Napier, W.M. (1984). Mon. Not. Roy. Astron. Soc. 208, 575-588.

Cochran, A.L. (1987). Astron. J., 93, 231-238.

Combi, M.R., and Delsemme, A.H. (1980). Astrophys. J., 237, 641-645.

Cowie, L.L., and Songaila, A. (1986). Ann. Rev. Astron. Astrophys. 24, 499-536.

Cronin, J.R., Pizzarello, S., and Cruikshank, D.P. (1988). In Meteorites and the Early Solar System, J.F. Kerridge and M.S. Matthews (eds.) University of Arizona Press, Tucson, pp. 819-857.

Danks, A.C., Lambert, D.L., Arpigny, C. (1974). Astrophys. J., 194, 745-751. 
Delsemme, A.H. (1975). Icarus, 24, 95-110.

Delsemme, A.H. (1981). In Comets and the Origin of Life, C. Ponnamperuma (ed.), D. Reidel Publishing Co., Dordrecht, pp. 141-159.

Delsemme, A.H. (1982). In Comets, L.L. Wilkening (ed.), University of Arizona Press, Tucson, pp. 85-130.

Delsemme, A.H. (1984). Origins of Life 14, 51-60.

Delsemme, A.H. (1985). Publ. Astron. Soc. Pacific, 97, 861-870.

Delsemme, A.H. (1987a). In Diversity and Similarity of Comets, Paris, ESA SP-278, pp. 19-30.

Delsemme, A.H. (1987b). Astron. Astrophys. 187, 913-918.

Delsemme, A.H. (1988). Phil. Trans. R. Soc. London A325, 509-523.

Delsemme, A.H. (1989). Sky and Telescope 77, 260-264.

Delsemme, A.H., and Miller, D.C. (1970). Planet. Space Sci. 18, 717.

Delsemme, A.H., and Miller, D.C. (1971). Planet. Space Sci. 19, 1229 and 1259.

Douglas, A.E., and Herzberg, G. (1941). Astrophys. J., 94, 381.

Draganic, I.G., and Draganic, Z.D. (1984). Icarus 60, 464-475.

Draine, B.T., and Lee, H.M. (1984). Astrophys. J., 285, 89-108.

Duncan, M., Quinn, T., and Tremaine, S. (1988). Astrophys. J., 328, L69-L74.

Eberhardt, P., Dolder, U., Schulte, W., et al. (1986). In ESLAB Sympos., ESA, Paris, ESA SP-250, vol. 1, p. 539.

Eberhardt, P., Krankowsky, D., Schulte, W., et al. (1987). Astron. Astrophys. 187, 481-484.

Evans, N.J., and Kutner, M.L. (1976). Astrophys. J., 204, L131-L134.

Fernandez, J.A., and Ip, W.H. (1981). Icarus 47, 470-479.

Fernandez, J.A., and Ip, W.H. (1983). Icarus 54, 377-387.

Finson, M.L., and Probstein, R.F. (1968a). Astrophys. J., 154, 327-352.

Finson, M.L., and Probstein, R.F. (1968b). Astrophys. J., 154, 353-380.

Fulle, M. (1987). Astron. Astrophys. 171, 327-335.

Fulle, M., Barbieri, C., and Cremonese, G. (1987). In Diversity and Similarity of Comets, ESA, Paris, ESA SP-278, pp. 639-644.

Goldsmith, P.F., Snell, R.L., Ericson, N.R., Dickman, R.L., Schloerb, F.P., and Irvine, W.M. (1985). Astrophys. J., 289, 613-617.

Greenberg, J.M. (1974). Astrophys. J., 189, L81-L85.

Greenberg, J.M. (1982). In Comets, L.L. Wilkening (ed.), University of Arizona Press, Tucson, pp. 131-163.

Greenberg, J.M., van de Bult, C.E., and Allamendola, L.J. (1983). J. Phys. Chem. 87, 4243-4260.

Greenberg, R., Wacker, J.F., Hartmann, W., and Chapman, C.R. (1978). Icarus 35, 126.

Grevesse, N. (1984a). In Frontiers of Astronomy and Astrophysics, R. Pallavicini (ed.), Ital. Astron. Soc., Florence, pp. 71-82.

Grevesse, N. (1984b). Physica Scripta T8, 49-58.

Grossman, J.N. (1988). In Meteorites and the Early Solar System, J.F. Kerridge and M.S. Matthews (eds.), University of Arizona Press, Tucson, pp. 680-696.

Grossman, J.N., Rubin, A.E., Nagahara, H., and King, E.A. (1988). In Meteorites and the Early Solar System, J. Kerridge and M.S. Matthews (eds.), University of Arizona Press, Tucson, pp. 619-696. 
Harmon, J.K., Campbell, D.B., Hine, A.A., Shapiro, I.I., and Marsden, B.G. (1989). Astrophys. J., 338, 1071-1093.

Hartmann, L., and Kenyon, S.J. (1985). Astrophys. J., 299, 462-478.

Harvey, P.M. (1985). In Protostars and Planets II, D.C. Black and M.S. Matthews (eds.) University of Arizona Press, Tucson, pp. 484-492.

Hawkins, I., and Jura, M. (1987). Astrophys. J. 317, 926-950.

Hayatsu, R., and Anders, E. (1981). In Cosmo- and Geochemistry, Vol. 99, Topics in Current Chemistry, Springer-Verlag, Berlin, pp. 1-37.

Herbst, E., and Klemperer, W. (1976). Physics Today 29, 32-39.

Hills, J.G. (1986). In Cosmogonical Processes, W.D. Arnett et al. (eds.), VNU Science Press, Utrecht, p. 285.

Hong, S.S., and Greenberg, J.M. (1980). Astron. Astrophys. 88, 194-202.

Huebner, W.F. (1987). Science 237, 628-629.

Ip, W.H., and Fernandez, J.A. (1988). Icarus 74, 47-62.

Irvine, W.M., and Knacke, R.F. (1988). In Origin and Evolution of Planetary Satellite Atmospheres, S.K. Atreya, J.B. Pollack, and M.S. Matthews (eds.), University of Arizona Press, Tucson, in press.

Irvine, W.M., Schloerb, P., Hjalmarson, A., and Herbst, E. (1985). In Protostars and Planets II, D.C. Black and M.S. Matthews (eds.) University of Arizona Press, Tucson, pp. 579-620.

Jenkins, E.B., Jura, M., and Loewenstein, M. (1983). Astrophys. J. 270, 88-104.

Jessberger, E.K., Christoforidis, A., and Kissel, J. (1988). Nature 332, 691-695.

Jessberger, E.K., Kissel, J., Fechtig, H., Krueger, F.R. (1986). In Comet Nucleus Sample Return, O. Melita (ed.), Paris, ESA SP-249, p. 27.

Jones, T.J., Hyland, A.R., and Allen, D.A. (1983). Mon. Not. Roy. Astron. Soc. 205, 187-190.

Kerridge, J.F., and Chang, S. (1988). In Protostars and Planets II, D.C. Black and M.S. Matthews (eds.) University of Arizona Press, Tucson, pp. 738-754.

Kissel, J., and Krueger, F.R. (1987). Nature 326, 755-760.

Kissel, J., Sagdeev, R.Z., Bertaux, J.-L., et al. (1986). Nature 321, 336-337.

Knacke, R.F., Geballe, T.R., Noll, K.S., and Tokunaga, A.T. (1985). Astrophys. J., 298, L67-L69.

Knacke, R.F., McCorkle, S., Puetter, R.C., Erickson, E.F., and Kratschmer, W. (1982). Astrophys. J., 260, 141-146.

Korth, A., Marconi, M.L., Mendis, D.A., et al. (1989). Nature 337, 53-55.

Kroto, H. (1988). Science, 242, 1139-1145.

Krueger, F.K., and Kissel, J. (1987). Naturwiss. 74, 312-316.

Kuiper, G. (1951, In Astrophysics: A Topical Symposium, J.A. Hynek (ed.), McGraw Hill, New York, pp. 357-424.

Lada, C.J. (1985, Ann. Rev. Astron. Astrophys. 23, 267-317.

Lambert, D.L. and Danks, A.C. (1983). Astrophys. J., 268, 428-446.

Larimer, J.W., and Anders, E. (1970, Geochim. Cosmochim. Acta 34, 367-387.

Larimer, J.W., and Wasson, J.T. (1988). In Meteorites and the Early Solar System, J.S. Kerridge and M.S. Matthews (eds.) University of Arizona Press, Tucson, pp. 416435.

Leger, A., Gauthier, S., Defourneau, D., and Rouan, D. (1983). Astron. Astrophys. 117, 164-169. 
Leger, A., and Puget, J.L. (1984). Astron. Astrophys. 137, L5-L8.

Levy, E.H. (1988). In Meteorites and the Early Solar System, J.F. Kerridge and M.S. Matthews (eds.) University of Arizona Press, Tucson, pp. 697-717.

Lewis, J.S. (1972a). Icarus 16, 241-252.

Lewis, J.S. (1972b). Earth and Planet. Sci. Letters 15, 286-290.

Lewis, J.S. (1974). Science 186, 440-443.

Lewis, J.S., Barshay, S.S., and Noyes, B. (1979). Icarus 37, 190-206.

Lewis, J.S., and Prinn, R.G. (1980). Astrophys. J., 238, 357-364.

Lewis, J.S., Tang, M., Wacher, J.F., Anders, E., and Steel, E. (1987). Nature 326, 160162.

Linke, R.A., and Goldsmith, P.F. (1980). Astrophys. J., 235, 437-451.

Lin, D.N.C., and Papaloisou, J. (1985). In Protostars and Planets II, D.C. Black and M.S. Matthews (eds.) University of Arizona Press, Tucson, pp. 981-1072.

Lynden-Bell, D., and Pringle, J.E. (1974). Mon. Not. Royl Astron. Soc. London 168, 603-637.

Martin, P.G., and Rogers, C. (1987). Astrophys. J., 322, 374-392.

Mason, B. (ed.) (1971). Handbook of Elemental Abundances In Meteorites, Gordon and Breach, New York.

Mathis, J.S., Rumpl, W., and Nordsiek, K.H. (1977). Astrophys. J., 217, 425-433.

Matsui, T., and Abe, Y. (1986). Nature 322, 526-528.

McDonnell, J.A.M., Alexander, W.M., Burton, W.M., et al. (1986). Nature 321, 338341.

McKellar, A. (1940). Publ. Astron. Soc. Pacific 52, 187.

Mendis, D.A., and Brin, G.D. (1977). Moon 17, 359-372.

Mendis, D.A., and brin, G.D. (1978). Moon and Planets 18, 77-89.

Mestel, L., and Spitzer, L. (1956). Mon. Not. Royl Astron. Soc. London 116, 505-514.

Morfill, G.E. (1988). Icarus 75, 371.

Morfill, G.E., Roser, W., Tscharnuter, W., and Volk, H. (1978). Moon and Planets 11, 211-22.

Morfill, G.E., Tscharnuter, W., and Volk, H.J. (1985). In Protostars and Planets, D.C. Black and M.S. Matthews (eds.) University of Arizona Press, Tucson, pp. 493-533.

Morrison, D. (1977, In Comets, Asteroids and Meteorites, A.H. Delsemme (ed.), University of Toledo, Toledo, pp. 177-184.

Mumma, M.J., Weaver, H.A., and Larson, H.P. (1987). Astron. Astrophys. 187, 419424.

Newburn, R.L., and Spinrad, H. (1985). Astron. J., 90, 2591-2608.

Nicolet, M. (1938). Zs. F. Astrophysik 15, 154.

Niederer, F.R., Eberhardt, P., and Geiss, T. (1985). Meteoritics 20, 716.

Olofsson, H. (1984). Astron. Astrophys. 134, 36-44.

Orofino, V., Colangeli, L., Bussoletti, E., and Strefella, F. (1987). Astrophys. Space Sci. 138, 127-140.

Pirronello, V. (1988). In Genesis and Propagation of Cosmic Rays, M.M. Shapiro and J.J. Wefel (eds.), NATO Adv. Sci. Inst. Ser. C. 22, D. Reidel Publishing Co., Dordrecht, pp. 299-313.

Rowan-Robinson, M. (1985). Phys. Scripta 11, 68-70. 
Safronov, V.S. (1969). In Evolution of Protoplanetary Clouds and Formation of the Earth and the Planets, Moscow: Nauka. Translation 1972 NASA TT F-677, Washington, D.C., pp. 69-89.

Safronov, V.S. (1972). In Motion, Evolution and Origin of Comets, Chebotarev et al. (eds.), IAU Symp. 45, D. Reidel Publishing Co., Dordrecht, and Springer-Verlag, N.Y.

Sakata, A., Setsuko, W., Okutsu, Y., Shintani, H., and Nakada, Y. (1983). Nature 301, 493-494.

Schramm, D. (1985). In Nucleosynthesis, W. D. Arnett and J. W. Truran (eds.), University of Chicago Press, Chicago, p. 106.

Sedlmayr, E. (1987, In Circumstellar Matter, IAU Symp. 122, pp. 543-544.

Sekanina, Z., and Miller, F.D. (1973). Science 179, 565-567.

Shu, F.H. (1977). Astrophys. J., 266, 555.

Shu, F.H., Adams, F.C., and Lizano, S. (1987). Ann. Rev. Astron. Astrophys. 25, 2382.

Skinner, C.J., and Whitmore, B. (1988). Mon. Not. Roy. Astron. Soc. London 231, 169-174.

Smith, B.A., and Terrile, R.J. (1984). Science 226, 1421-1424.

Strazzulla, G., Calcagno, L., and Foti, G. (1983). Mon. Not. Roy. Astron. Soc. 204, 5962.

Swart, P, K., Grady, M.M., Pillinger, C.T., Lewis, R.S., and Anders, E. (1983). Science 220, 406.

Swings, P., and Rosenfeld, L. (1937). Astron. J., 86, 483.

Truran, J.W. (1985). In Nucleosynthesis, W.D. Arnett and J.W. Truran (eds.), University of Chicago Press, Chicago, p. 292.

Urey, H.C., and Craig, H. (1953). Geochim. Cosmochim. Acta. 4, 36-82.

Walter, F.M. (1986). Astrophys. J., 306, 573-586.

Wannier, P. (1980). Ann. Rev. Astron. Astrophys. 18, 399-437.

Watson, D.M. (1984). In Galactic and Extragalactic Infrared Astronomy, M.F. Kessler, and J.P. Phillips (eds.), D. Reidel Publishing Co., Dordrecht, pp. 195-219.

Wdowiak, T.J., Flikinger, G.C., and Cronin, J.R. (1988). Astrophys. J., 328, L75-L79.

Weast, R.C., Astle, M.J., and Beyer, W.H. (eds.) (1984). CRC Handbook of Chemistry and Physics, CRC Press, Boca Raton, Florida.

Weidenschilling, S.J. (1988). In Meteorites and the Early Solar System, J.F. Kerridge and M.S. Matthews (eds.), University of Arizona Press, Tucson, pp. 348-371.

Weissman, P.R. (1985). In Protostars and Planets II, D.C. Black and M.S. Matthews (eds.) University of Arizona Press, Tucson, pp. 895-919.

Welch, W.J., Dreher, J.W., Jackson, J.M., Tereby. S., and Vogel, S.N. (1987). Science $138,1550-1555$.

Wetherill, G.W. (1980). Ann. Rev. Astron. Astrophys. 18, 77-113.

Wetherill, G.W., and Chapman, C.R. (1988). In Meteorites and the Early Solar System, J.F. Kerridge and M.S. Matthews (eds.) University of Arizona Press, Tucson, pp. 3567.

Whipple, F.L. (1977). In Comets, Asteroids and Meteorites, A.H. Delsemme (ed.), University of Toledo Press, Toledo, pp. 25-35.

Willems, F.J., and deJong, T. (1988). Astron. Astrophys. 196, 173-184.

Willner, S.P., Gillett, F.C., et al. (1982). Astrophys. J., 243, 174-187. 
Wood, J.A., and Morfill, G.E. (1988). In Meteorites and the Early Solar System, J.F. Kerridge and M.S. Matthews (eds.), University of Arizona Press, Tucson, pp. 329347.

Wyckoff, S., Lindholm, E., Wehinger, P.A., Petersson, B.A., Zucconi, J.M., and Festou, M.C. (1989). Astrophys. J., 339, 448-500.

Zinner, E., Ming, T., and Anders, E. (1987). Nature 330, 730-732. 